Guo H, Dong Y, Bastidas-Arteaga E (2021). Probabilistic Failure Analysis, Performance Assessment, and Sensitivity Analysis of Corroded Reinforced Concrete Structures. Engineering Failure Analysis. Article ID: 105328 https://doi.org/10.1016/j.engfailanal.2021.105328

\title{
Probabilistic Failure Analysis, Performance Assessment, and Sensitivity Analysis of Corroded Reinforced Concrete Structures
}

\author{
Hongyuan Guo ${ }^{1,2,3}$, You Dong ${ }^{1, *}$, Emilio Bastidas-Arteaga ${ }^{4,5}$, and Xiang-Lin Gu ${ }^{2,3}$
}

1. Department of Civil and Environmental Engineering, The Hong Kong Polytechnic University, Hong Kong, China

2. Key Laboratory of Performance Evolution and Control for Engineering Structures of Ministry of Education, Tongji University, 1239 Siping Rd., Shanghai 200092, China

3. Department of Structural Engineering, College of Civil Engineering, Tongji University, 1239 Siping Rd., Shanghai 200092, China

4. University of Nantes, GeM UMR CNRS 6183, Nantes, France

5. La Rochelle University, LaSIE UMR CNRS 7356, Nantes, France

\begin{abstract}
A better understanding of the mechanical performance and the failure modes of corroded reinforced concrete $(\mathrm{RC})$ structures is crucial for implementing measures that reduce failure risks. Therefore, this paper proposes a probabilistic numerical framework to estimate the structural performance and to identify the failure modes as well as the main influencing parameters affecting the safety of corroded RC structures. This framework comprehensively combines experimental data, finite element method (FEM), and polynomial chaos expansion (PCE) modeling. First, the FEM for failure analysis is developed and verified with a 26-year-old corroded RC beam. The investigated case considers the effects of corrosion degree and bond behavior of the steel-concrete interface on the mechanical properties and failure mode of the corroded RC beam. Second, PCE surrogate models for serviceability and ultimate limit states are established by combining the sampling technique (e.g., Sobol sequences) and the validated FEM model. Finally, a global sensitivity analysis is conducted using the PCE model. Several illustrative cases are presented to analyze, in deterministic and probabilistic manners, the failure modes and the sensitivities of material properties and geometry characteristics for both serviceability and ultimate limit states. The results of this study could provide useful insights for understanding the main failure modes of $\mathrm{RC}$ structures under different corrosion scenarios.
\end{abstract}

Keywords: Reinforced concrete structure; polynomial chaos expansion; global sensitivity analysis; failure analysis.

\footnotetext{
** Corresponding Author

E-mail address: you.dong@polyu.edu.hk Tel.: +852-34008818
} 


\section{List of acronyms}

FEM: Finite element method

MCS: Monte Carlo simulation

PCE: Polynomial chaos expansion

RC: $\quad$ Reinforced concrete

RSM: Response surface method

SA: $\quad$ Sensitivity analysis

SLS: $\quad$ Serviceability limit state

ULS: Ultimate limit state

\section{Introduction}

Under aggressive chloride-contaminated environments, reinforcement corrosion might occur, reducing the serviceability and safety of reinforced concrete (RC) structures and further causing a long-term impact on society and the environment [1-3]. A survey published by NACE International indicated that the global cost of corrosion is around 2.5 trillion US dollars, which corresponds to about $3.4 \%$ of global Gross Domestic Product in 2013 [4]. Thus, concerning the high corrosion cost, it is of great importance to raise awareness of improved maintenance practices that reduce cost, environmental and social impacts. Towards this aim, a robust and unified assessment methodology for the performance assessment of RC structures needs to be proposed.

Failure analysis and performance assessment of corroded RC structures are based on deterministic and probabilistic approaches. Experiments [5,6], analytical methods [7], and finite element methods (FEM) [8,9] are typically used in deterministic studies. For instance, Ye et al. [6] conducted an experimental failure analysis of 13 corroded RC beams and found that these beams could fail by shear when the corrosion level of stirrups reaches a critical value. Experiments could provide reliable and intuitive findings for model validation and/or lifetime modeling but are usually time-consuming and costly. Thus, many scholars proposed analytical models to perform the failure analysis for corroded RC structures. For instance, Recupero et al. [7] developed an analytical model to predict the shear and flexural capacity of $\mathrm{RC}$ elements and validated it with a data set of experimental results. However, due to the difficulty in depicting the complex mechanisms of reinforcement corrosion and structural 
behavior, the analytical models generally deviate significantly from the experimental results. Owing to the rapid development of computing technology, FEM has also been applied to simulate and evaluate the structural performance in time with high accuracy [10]. For example, Kallias et al. [8] applied FEM for sensitivity analysis (SA) to investigate the effects of concrete strength and bond deterioration on the performance of corroded RC beams. Thus, deterministic analysis has been successfully adopted in the performance evaluation and failure analysis of corroded RC structures.

Considering the uncertainties and spatial variability inherent to the surrounding environmental conditions, deterioration processes, models, and material properties, it is a requirement to conduct a comprehensive failure/performance analysis of corroded RC structures $[11,12]$. Therefore, the probabilistic analysis methods applied to corroded RC structures attracted the attention of scholars and engineers [13]. Many scholars applied analytical models and/or Monte Carlo simulation (MCS) to carry out probabilistic analyses $[14,15]$. For instance, Li and Melchers [16] utilized a probabilistic analytical model to carry out a SA to determine the critical parameters for the corroded RC beam. Other studies $[15,17]$ considered pitting corrosion and performed reliability analysis with respect to the spatial variability of a corroded RC beam. However, the models mentioned above might neglect some critical information, such as the bond behavior of corroded reinforcement [18], deflection, cracking patterns on RC beam [19]. Many scholars adopted probabilistic FEM-based approaches [18,20] to address the above issues. Bergmeister et al. [21] proposed a probabilistic assessment framework based on Latin hypercube sampling and non-linear FEM to perform sensitivity and reliability analysis. Zhang et al. [18] carried out a reliability estimation of a corroded RC beam by using FEM and X-ray photographs to account for the spatial variability of corroded steel bars.

The FEM-based probabilistic analysis could provide reliable and comprehensive lifetime assessments; however, a realistic prediction might also impose a significant computational burden due to the complexity of the numerical models, including a set of non-linear and coupled differential equations, resolutions in space and time, and a large number of 
parameters. Thus, surrogate models are useful tools for alleviating computational costs in FEM-based probabilistic analysis. Among these models, statistical methods, such as the response surface method (RSM), were intended to establish a surrogate model for a RC beam to reduce the cost of MCS [18] and conduct SA [22]. However, studies have shown that RSM may not be feasible for analyzing global sensitivity due to its limited accuracy [23]. Polynomial chaos expansion (PCE) based probabilistic analysis methods have received extensive attention due to their high accuracy and efficiency in establishing surrogate models $[24,25]$. In addition, PCE-based methods allow the SA of random variables, i.e., global SA, by integrating full randomness and variability of input and output variables. However, few studies have been done in PCE-based probabilistic analysis for corroded RC structures. For instance, Bastidas-Arteaga et al. [25] developed a PCE-based probabilistic model for global SA of RC structures suffering from chloride-induced corrosion, but their study focused on the initiation period (Serviceability limit state, SLS) rather than the propagation period (Ultimate limit state, ULS). Thus, it is of vital importance to conduct a complete analysis of structural performance, considering both SLS and ULS.

In this study, we propose a comprehensive framework for probabilistic failure analysis, performance assessment, and sensitivity analysis of corroded RC structures. It combines experimental data, FEM, and PCE. We particularly focus on existing corroded RC structures where the current corrosion condition of rebars and the presence of cracks provide more uncertainties to the performance assessment at the moment of the inspection and/or the evaluation of the remaining capacity. The basic concepts and algorithms of the proposed framework are introduced in Section 2. Then, in Section 3, using a corroded RC beam as one example, the FEM model is established in detail. The principles and algorithms of PCE are introduced in Section 4. Section 5 presents the results associated with the illustrative example. The first subsection in Section 5 verifies the feasibility and accuracy of the proposed FEM model based on a study of a 26-year-old corroded RC beam. The second subsection focuses on the development of the PCE and its application for sensitivity and failure analyses. 


\section{Performance assessment and failure analysis of corroded RC structures}

In this study, the performance assessment of corroded reinforced concrete (RC) structures focuses on different components of the structural response, such as the curves of external loads versus deformations, the distribution of reinforcement stresses, and concrete strains, and cracking patterns. Based on the structural response, the evolution of the RC structures under external loads can be studied; the limit states of RC structures, including the serviceability limit state (SLS) and ultimate limit state (ULS), can be determined; and more importantly, the potential failure mode and pattern could be deduced.

The general computational framework of performance assessment is presented in Fig. 1. As indicated, the proposed framework consists of ten steps. The first two steps are the determination of geometric and mechanical information of the RC structure (e.g., remaining cross-sectional section of rebars and the presence of cracks, among others.), which depends on the investigated example. In this paper, the information is obtained from experiments to validate the numerical results. Due to the experimental costs, it is not feasible to conduct a large number of experiments, so that numerical analysis is needed to perform failure analysis by considering different scenarios. The main inputs of this numerical analysis are the geometry information, constitutive models of concrete, corroded steel bars, and bond-slip, boundary conditions, among others. The third step is to perform finite element method (FEM) simulation using commercial FEM software, DIANA 10.3 [26], to account for the above-mentioned parameters. Other software could also be adopted within the structural analysis process. Detailed processes associated with FEM, including geometry modeling and material constitutive models, are introduced in Section 3. 


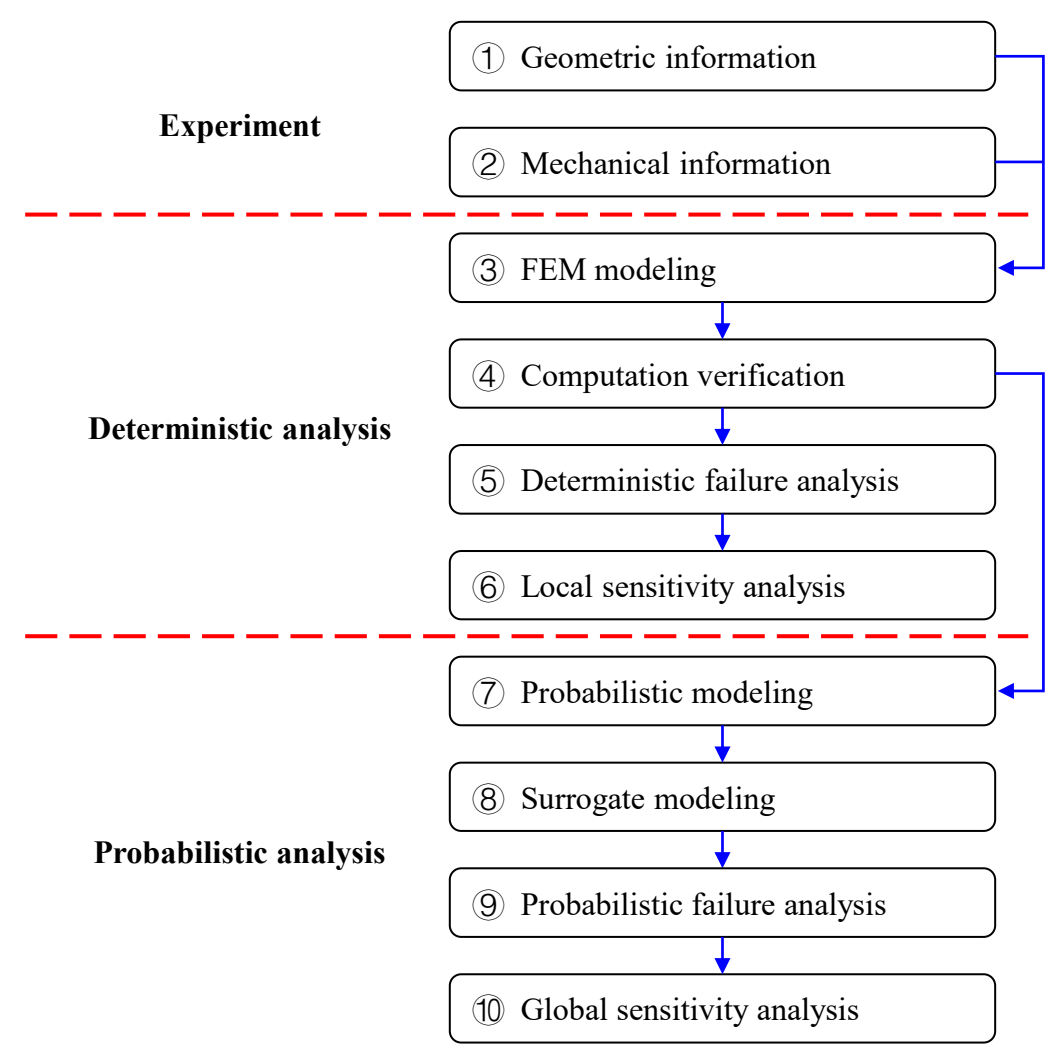

Fig. 1. General framework for performance assessment of corroded RC structures

The third to sixth steps are devoted to perform deterministic analysis, and the primary goal is to demonstrate the applicability and accuracy of numerical models by comparing them with experimental data, i.e., the fourth step. The information on the geometry and mechanical parameters of the corroded RC beam is mainly derived from the first and second steps, i.e., experimental studies on existing structures. Apart from the experimental verification in the fourth step, different assumptions (e.g., corrosion degree of reinforcement and constitutive models of materials) are made and assessed. The fifth step (failure analysis) is conducted to investigate the failure mechanisms. Subsequently, the sixth step, i.e., local sensitivity analysis (SA), is performed to study different parameters on structural performance (e.g., the effect of corrosion degree on structural behavior and the spatial effect on stress and crack distribution).

On the other hand, probabilistic analysis (the seventh to tenth steps) is needed to account for the uncertainties associated with different variables. For instance, in the seventh step, some geometrical parameters (e.g., the geometry of corroded rebar) are represented by probabilistic models (Section 3.1.2). In this study, a low discrepancy sequence-based Monte 
Carlo simulation (MCS) (e.g., Sobol sequences) is conducted to generate critical information of the FEM model and perform the FEM analysis. However, brute MCS is computationally expensive, and global SA is not easy to be conducted. To tackle this problem, a surrogate model (Section 4) is established in the eighth step. In this study, polynomial chaos expansion (PCE) is employed for the surrogate modeling due to its high accuracy and efficiency in global SA as the sensitivity factors could be computed directly through the coefficients of PCE. Then, the built surrogate model is employed in the ninth and tenth steps for probabilistic failure analyses and global SA, respectively.

\section{FEM model of a corroded RC beam}

\subsection{Spatial variability of corroded rebars}

In this study, a corroded reinforced concrete (RC) beam is used as an example to illustrate the proposed methodology. As shown in Fig. 2, the length and cover thickness of the beam are $L$ and $c$, respectively, and the cross-sectional width and height are denoted as $b$ and $h$, respectively. The reinforcement layout of this $\mathrm{RC}$ beam is: $n_{t}$ tension bars, $n_{\mathrm{c}}$ compression bars, and $n+1$ stirrup bars with $n_{\mathrm{sv}}$ vertical legs and $s_{v}$ stirrup spacing. Deterministic and probabilistic approaches could be implemented to consider the spatial variability of corroded rebars. Both approaches are summarized in the following sections.
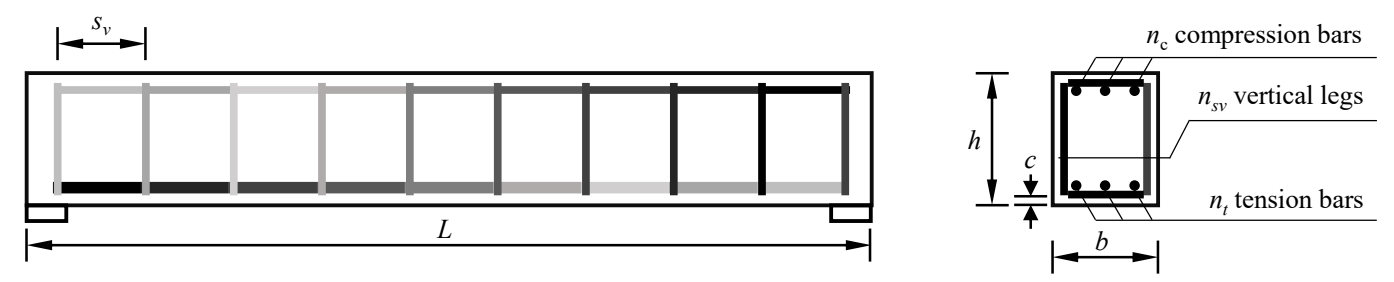

Fig. 2. Geometry schematic of the RC beam

\subsubsection{Deterministic modeling}

Deterministic modeling is commonly used in experimental validations [9,27]. In previous studies, the geometry of corroded steel bars is represented by a cylinder with a reduced diameter. Also, based on the assumption of uniform corrosion, the corrosion degree is 
quantified by an average corrosion degree $\eta_{\text {ave }}$ [28]. However, non-uniform and pitting corrosion are common phenomena in practice, which would induce spatial variability and the local corrosion degree $\eta_{\mathrm{s}}[15]$. Thus, it is necessary to establish a spatial variability model of non-uniform corrosion accounting for the previously mentioned effects.

Characterizing the spatial variability of corroded rebars is not an easy task. To date, at least three methods, based on experimental procedures, have been used to achieve this goal, as follows:

(1) to cut the entire corroded steel bar into several segments along its axis, then to measure the mass of each segment and finally obtain the distribution of mass loss ratio along the axis [29];

(2) to measure the residual diameter of steel bar along the axis using a Vernier caliper, then to compute the distribution of diameter loss along the axis [30]; and

(3) to employ a three-dimensional light scanner [31] or X-ray photograph [18] to obtain a 2D/3D geometry model of corroded steel bars directly and then analyze the distribution of cross-sectional areas.

The first method could reflect the gravimetric loss of steel bars but damages the specimen. The third method could reveal the complete geometry information of the steel bar with relatively high accuracy; however, the used measurement devices are relatively expensive, and advanced numerical methods are required to analyze the output. In order to balance measurement accuracy and experimental cost, the second method is usually regarded as a compromise choice, which is convenient to be used in practical engineering. Also, the Vernier caliper is a cheaper tool than the devices in the third method, and it causes less damage to the structure compared with the first method.

Once the spatial geometry of the corroded steel bar is obtained, the spatial variability of longitudinal (tension and compression) bars would be simplified to a series of bar elements with different circular cross-sections as the input for the finite element method (FEM) model. For the $n_{\mathrm{t}}$ tension bars and $n_{\mathrm{c}}$ compression bars, the first step is to divide each longitudinal bar into $n$ zones. Then, at the $i$-zone, the maximum diameter loss of $j$-th tension bar, $p_{t, \text { max }, i, j}$ 
and $k$-th compressive bar, $p_{\mathrm{c}, \max , i, k}$ are measured and then used to calculate the minimum cross-sectional areas by Eqs. (1) and (2). Thus, the cross-sectional areas of the bar elements within each zone and longitudinal bar, i.e., cross-sectional area of tension bars, $A_{t, i, j}(i=1$, $2, \ldots, n$ and $\left.j=1,2, \ldots, n_{t}\right)$ and compression bars, $A_{\mathrm{c}, i, k}\left(i=1,2, \ldots, n\right.$ and $\left.k=1,2, \ldots, n_{\mathrm{c}}\right)$, are represented by their minimum cross-sectional area. For the $n+1$ stirrup bars, each stirrup bar is divided into $n_{\mathrm{sv}}$ vertical legs. Next, at the $l$-th vertical leg, the maximum diameter loss $p_{s v, \max , m, l}$ at the $m$-th stirrup bar is also measured to compute the minimum cross-sectional area $A_{\mathrm{sv}, m, l}\left(m=1,2, \ldots, n+1, l=1,2, \ldots, n_{\mathrm{sv}}\right)$ by Eq.(3).

$$
\begin{aligned}
A_{t, i, j} & =\frac{\pi}{4}\left(D_{t 0}-p_{t, \max , i, j}\right)^{2} \\
A_{c, i, k} & =\frac{\pi}{4}\left(D_{c 0}-p_{c, \text { max }, i, k}\right)^{2} \\
A_{s v, m, l} & =\frac{\pi}{4}\left(D_{s v 0}-p_{s v, \text { max }, m, l}\right)^{2}
\end{aligned}
$$

in which $D_{t 0}, D_{\mathrm{c} 0}$, and $D_{\mathrm{sv} 0}$ are the expected diameters of uncorroded tension bar, compression bar, and stirrup, respectively. Also, local corrosion degree $\eta_{\mathrm{s}}$ could be quantified by the difference ratio between the original and the minimum cross-sectional area from Eqs.(1)-(3).

Besides, to evaluate the bond strength between the steel-concrete interface, the surface area of steel bar $A_{\text {surf }}$ of the corroded steel bar can be computed as

$$
A_{\text {surf }}=\pi\left(D_{0}-p\right) L_{b a r}
$$

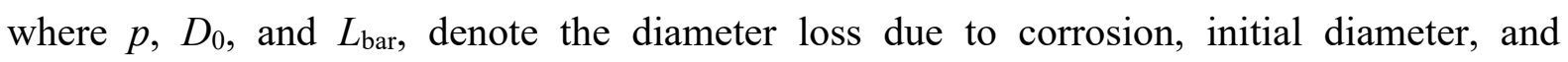
longitudinal length, respectively.

\subsubsection{Probabilistic modeling}

A probabilistic approach is more suitable to account for the spatial variability of corroded rebars geometry in a more realistic way. The corroded geometry could be defined by the pitting factor, which is the ratio of the maximum pit depth to the average pit depth of the corroded steel bar [32]. By employing the Type-I extreme distribution, Stewart and Alharthy [15] developed the probabilistic model of pitting factor to conduct reliability analysis. Besides, Darmawan [33] improved the model of pitting factor by considering time parameters 
and corrosion rates. However, the pitting factor-based probabilistic model assumes one-single pit. Later, some scholars have made some improvements in the stochastic modeling of the corroded steel bar. For instance, Tang et al. [34] proposed to use a mixed normal distribution to model the cross-sectional area, but it neglects longitudinal correlations.

On the other hand, considering the complex geometry and random distribution of pits in the cross-section of a corroded steel bar, Gu et al. [12] proposed the corrosion non-uniformity factor, $R$, defined as the ratio of the average cross-sectional area to the minimum cross-sectional area, i.e.,

$$
R=A_{a v} / A_{\min }=\pi D_{0}^{2}\left(1-\eta_{a v e}\right) / A_{\min }
$$

in which $A_{a v}$ and $A_{\min }$ are the average cross-sectional area and the minimum cross-sectional area, respectively; $\eta_{\text {ave }}$ is the average corrosion ratio of the steel bar; and $D_{0}$ is the initial diameter of the rebar. Factor $R$ also follows the Type-I extreme distribution, and distribution parameters $\mu$ and $\sigma$ could be computed by $[11,12]$

$$
\begin{gathered}
\mu=3.35 \eta_{\mathrm{s}} \exp \left(-0.236 i_{\text {corr }}\right)+0.12 \eta_{\mathrm{s}}+\sigma \ln \left(A_{s} / A_{s 0}\right)+1.01 \\
\sigma=0.3371 \eta_{s}+0.0006
\end{gathered}
$$

where $i_{\text {corr }}\left(\mu \mathrm{A} / \mathrm{cm}^{2}\right)$ is the corrosion current density; and $A_{s}\left(\mathrm{~mm}^{2}\right)$ and $A_{s 0}\left(\mathrm{~mm}^{2}\right)$ are the surface areas of the $L_{b a r}$ and $50 \mathrm{~mm}$ length of steel bar.

$$
A_{s}=L_{b a r} \pi D_{0}, A_{s 0}=50 \pi D_{0}
$$

For tension and compression bars, $L_{\mathrm{bar}}$ can be determined by the length of each zone, while for stirrup bars, the $L_{\text {bar }}$ can be determined by the vertical height of the stirrup leg. The factor $R$ and the minimum cross-sectional area of each element are statistically independent of the others. Given the samples of factor $R$ and other parameters, e.g., $i_{\text {corr }}$ and $n_{\text {ave, }}$, the minimum cross-sectional areas of corroded steel bars could be computed through Eq. (5), and assigned into different elements of steel bars. 


\subsection{Constitutive model of materials}

\subsubsection{Concrete}

The total strain-based crack model is applied for the constitutive model of concrete, which is based on total strain and the modified compression field theory [35]. In this model, the stress-strain relationship is evaluated in the principal directions of the strain vector, i.e., the coaxial stress-strain concept. In terms of the relationship between the directions of crack and principal stress, two types of crack models are presented:

(1) Fixed crack model, in which the crack direction would not change with the principal stress once cracking happens.

(2) Rotating crack model, in which the crack direction would keep changing with the principal stress.

In the fixed crack model, the shear resistance of the cracks is modeled by the shear retention factor, reflecting the aggregate interlock effect caused by cracked concrete. In the rotating crack model, there exist no shear stresses on the crack plane, which simplifies the analysis and receives a large scale of application [36,37]. This study applies the rotating crack model.

Tensile and compressive behaviors of concrete are illustrated in Fig. 3. For the tensile behavior of concrete, the stress increases linearly before reaching the ultimate tensile strength. Then, it drops following a tension softening model developed by Hordijk [38]. For the compressive behavior of concrete, the stress increases/decreases following parabolic curves [39], as shown in Fig. 3.

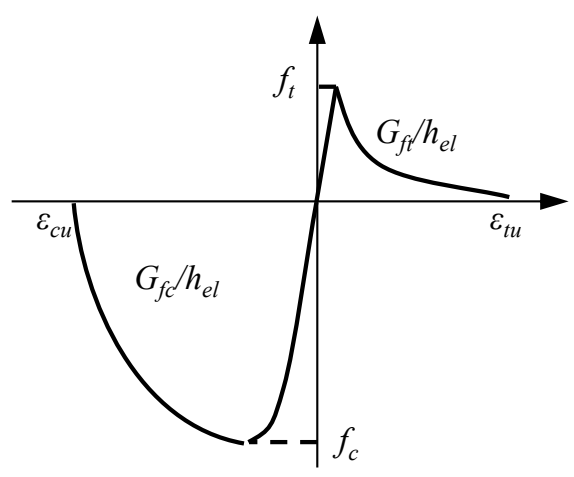

Notation: 


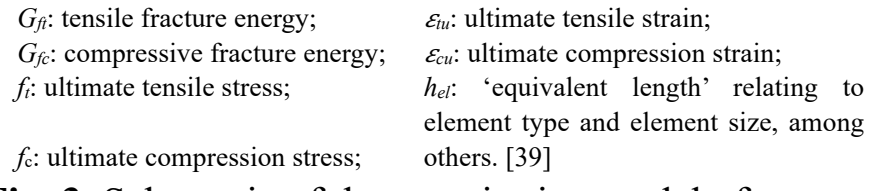

Fig. 3. Schematic of the constitutive model of concrete

The ultimate tensile and compression strains are computed by the tensile and compressive fracture energies $G_{f t}$ and $G_{f c}(\mathrm{kN} / \mathrm{m})$, respectively. $G_{f t}$ can be calculated by a formula proposed by FIB Model Code 2010 [40]

$$
G_{f t}=0.073 f_{c}^{0.18}
$$

In this study, the compressive fracture energy $G_{f c}$ is supposed to be about 100 times of $G_{f t}$ [39]. A reduction factor is proposed to consider the influence of cracking on the compressive strength [41], and the lower bound of the reduction factor is assumed as 0.6 in this study.

\subsubsection{Corroded reinforcement}

In general, the corrosion of a RC beam affects not only the geometry but also the constitutive model of the steel bars. In most of the available studies, the constitutive models of steel bars supposed that yield and ultimate strengths would reduce with corrosion degree $[2,8]$. However, previous studies proved that corroded reinforcement might fail at the location of the minimum cross-sectional area, and its actual strength does not change if the stress at the broken section is taken to measure its strength [12]. Besides, in previous studies related to the FEM analysis of corroded RC structures, reinforcement is usually modeled by bilinear/ideal elastoplastic constitutive models to simplify the stress-strain relationship [8,42]. However, the deformation ability and nominal strength of corroded reinforcement (nominal strength is the yield/ultimate tensile force divided by the uncorroded cross-sectional area or average cross-sectional area) decreases significantly with corrosion degree $[43,44]$. Studies showed that the failure mode of corroded steel bar would change from ductile failure to brittle failure once its corrosion degree $\eta_{\mathrm{s}}$ exceeds about $20 \sim 30 \%[45,46]$.

In this study, by combining the existing studies in $[12,45]$, a new trilinear constitutive model of corroded steel bars is proposed, as depicted in Fig. 4. Given that the elastic modulus 
$E_{\mathrm{s} 0}$, actual yield strength $f_{\mathrm{y} 0}$, and ultimate strength of corroded steel bar $f_{u 0}$ remain unchanged, the harden strain and ultimate strain decrease with the corrosion degree. The evolution of the constitutive relationship of a corroded steel bar subjected to tension is described by Eqs. (10) and (11) [47]. For reinforcement, the Von Mises plasticity model is used, assuming isotropic hardening.

$$
\varepsilon_{s h c}=\left\{\begin{array}{c}
\frac{f_{y 0}}{E_{s 0}}+\left(\varepsilon_{s h 0}-\frac{f_{y 0}}{E_{s 0}}\right)\left(1-\frac{\eta_{s}}{\eta_{s, c r}}\right), \eta_{s} \leq \eta_{s, c r} \\
\varepsilon_{s y c}=\frac{f_{y c}}{E_{s 0}}, \eta_{s}>\eta_{s, c r} \\
\varepsilon_{s u c}=\exp \left(-\beta_{\delta} \eta_{s}\right) \varepsilon_{s u 0},
\end{array}\right.
$$

where $\eta_{\mathrm{s}, \mathrm{cr}}$ is the critical corrosion degree $\left(20 \sim 30 \%\right.$ [45]); $\varepsilon_{s h 0}$ and $\varepsilon_{s u 0}$ are the harden strain and ultimate strain of non-corroded steel bar; $\mathcal{E}_{s h c}$ and $\varepsilon_{s u c}$ are the harden strain and ultimate strain of corroded steel bar; and $\beta_{\delta}=2.093$ and 2.501 for salt spray induced corrosion and natural corrosion (corroded steel bars obtained under real environmental conditions), respectively [48].

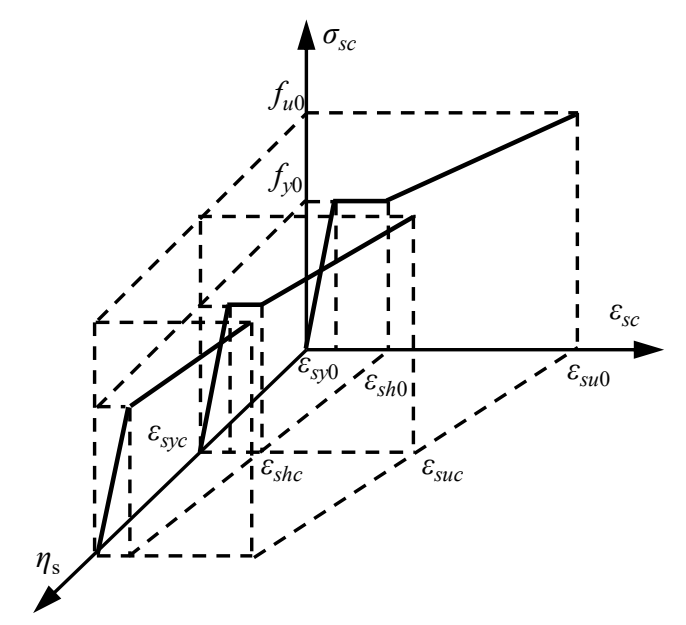

Fig. 4. Constitutive models of corroded steel bars.

\subsubsection{Bond-slip}

If a $\mathrm{RC}$ beam is well-anchored and no corrosion happens, the reinforcement could be supposed to be well embedded inside the concrete. Otherwise, bond-slip behavior must be considered in the FEM. The bond-slip relationship could be assigned to the interface between 
the steel bar and concrete directly. Employing the bond-slip model proposed by Kallas and Rafiq [8], the bond stress $\tau$ versus slip $s$ could be described as follows

$$
\begin{aligned}
\tau & =\left\{\begin{array}{l}
\tau_{1}\left(s / l_{1}\right)^{0.3}, 0 \leq s<s_{0} \\
\left(s-s_{0}\right) /\left(s_{1}-s_{0}\right) \cdot(1-\alpha) \cdot \tau_{\max }+\alpha \cdot \tau_{\max }, s_{0} \leq s<s_{1}, \\
\left(s-s_{1}\right) /\left(s_{1}-s_{2}\right) \cdot(1-\beta) \cdot \tau_{\max }+\tau_{\max }, s_{1} \leq s<s_{2}
\end{array}\right. \\
\tau_{1} & =2.57 f_{c}^{0.5}, s_{0}=l_{1}\left(\alpha \tau_{\max } / \tau_{1}\right)^{1 / 0.3}, \\
s_{1} & =l_{1} \exp \left[(1 / 0.3) \ln \left(\tau_{\max } / \tau_{1}\right)\right]+l_{0} \ln \left(\tau_{1} / \tau_{\max }\right)
\end{aligned}
$$

where $\alpha$ and $\beta$ denote the factors of the bond model (i.e., $\alpha=0.7$ and $\beta=0.3$ ); $l_{0}, l_{1}$, and $s_{2}$ are $0.4 \mathrm{~mm}, 0.15 c_{0}$, and $0.35 c_{0}$ ( $c_{0}$ is the rib spacing, e.g., $8 \mathrm{~mm}$ [8]), respectively; and $\tau_{\max }$ is the maximum bond strength of concrete beam with deformed rebars. In this study, $\tau_{\max }$ is evaluated by an empirical model [49]:

$$
\tau_{\max }=\left(k_{1}+k_{2} \eta_{s}\right)\left[0.55+0.24\left(c / d_{b}\right)\right] \sqrt{f_{c}}+0.191 \cdot A_{s v} f_{y} /\left(s_{v} \cdot d_{b}\right)
$$

where $c$ is the cover thickness of concrete; $d_{\mathrm{b}}$ is the diameter of the deformed tension rebar; $A_{s v}$ is the cross-sectional area of stirrup bars; $s_{v}$ is the stirrup spacing; and $k_{1}$ and $k_{2}$ are the empirical factors accounting for the reduced contribution of concrete towards bond strength, relating to the corrosion current density of steel bar. For the corrosion current density of 40 $\mu \mathrm{A} / \mathrm{cm}^{2}, k_{1}$ and $k_{2}$ are 1.003 and -0.037 [50], respectively; For the corrosion current density of $90 \mu \mathrm{A} / \mathrm{cm}^{2}, k_{1}$ and $k_{2}$ are 1.104 and -0.024 [50], respectively.

\section{Surrogate model and global sensitivity analysis}

\subsection{General description}

To conduct the global sensitivity analysis (SA), the finite element method (FEM) is combined with polynomial chaos expansion (PCE) surrogate modeling using the MATLAB ${ }^{\circ}$ software.

Fig. 5 describes the methodology used to create the surrogate models. Monte Carlo simulation (MCS) is used to propagate uncertainty in FEM and generate $N$ input and output variables necessary to build the PCE surrogate model presented in Section 4.2. In this process, it is necessary to determine the distributions of random input variables (e.g., material mechanical parameters, the cross-sectional area of steel bar), output variables (e.g., ultimate 
and serviceability capacity indicators). Meanwhile, a type of low discrepancy sequence, Sobol nets [51], is employed to improve the sampling efficiency. Once the PCE model is established, SA could be carried out through the approaches described in Sections 4.3, respectively.

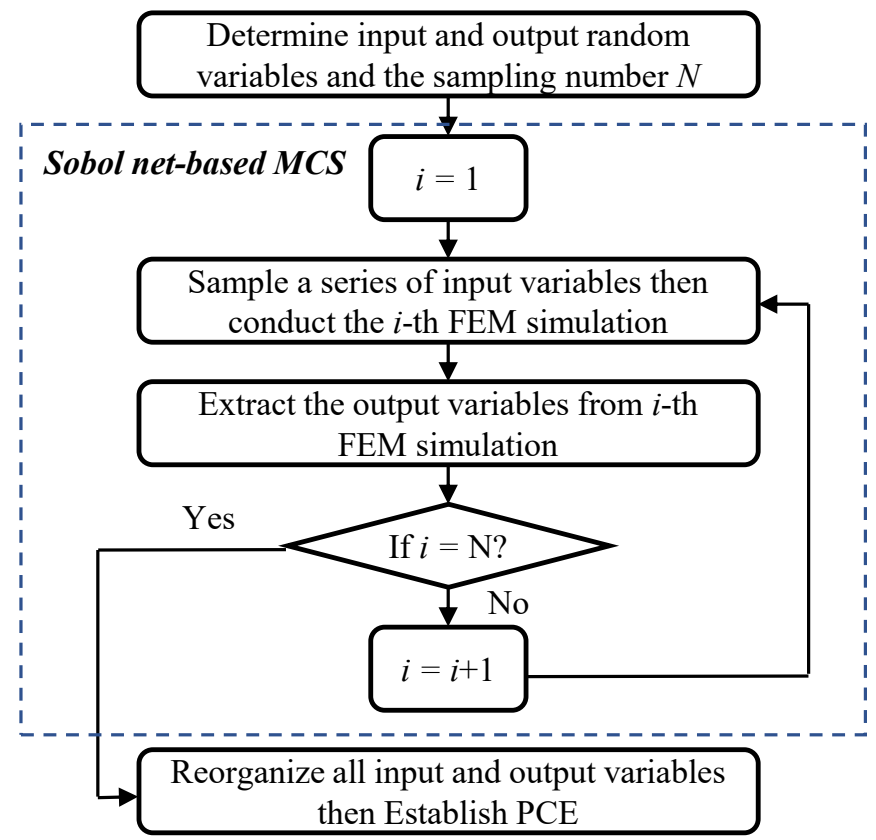

Fig. 5. Establishment processes of PCE

\subsection{Surrogate modeling: polynomial chaos expansion}

The idea of PCE is to establish a surrogate model $\Gamma_{P C E}$ by expanding the target response onto the basis of the probability space from input variables. All uncertain input variables $\boldsymbol{x}=$ $\left\{x_{1}, \ldots, x_{N}\right\}$ should be represented by a marginal probability density function (PDF) [52]. Meanwhile, the system response $g(\boldsymbol{x})$ could be approximately replaced by an orthogonal polynomial basis $\Gamma^{P C E}[53]$

$$
\begin{aligned}
& g(\boldsymbol{x}) \approx \Gamma^{P C E}=\sum_{j=0}^{M-1} a_{j} \Psi_{j}(\boldsymbol{x})=a_{0}+\sum_{i=1}^{M} \sum_{j \in I_{i}} a_{j} \Psi_{j}\left(x_{j}\right)+\sum_{1 \leq i_{1} \leq i_{2} \leq M} \sum_{j \in I_{i, j}, i_{2}} a_{j} \Psi_{j}\left(x_{i_{1}}, x_{i_{2}}\right)+\ldots \\
& +\sum_{1 \leq i_{1} \leq \ldots \leq i_{s} \leq M} \sum_{j \in I_{i_{1}, \ldots, i_{s}}} a_{j} \Psi_{j}\left(x_{i_{1}}, \ldots, x_{i_{s}}\right)+\ldots+\sum_{j \in I_{i_{1}, \ldots, i_{M}}} a_{j} \Psi_{j}\left(x_{i_{1}}, \ldots, x_{i_{M}}\right), M=\frac{(N+p) !}{N ! p !}
\end{aligned}
$$

where $I_{i 1, \ldots, i \mathrm{M}}$ denotes the set of non-zero indices $\left(i_{1}, \ldots, i_{\mathrm{M}}\right) ; a_{j}$ and $p$ are the coefficient and order of PCE, respectively; and $\Psi_{j}(\boldsymbol{x})$ is the product of one-dimensional polynomials $\phi_{a j}$. 
Supposing the random variables within $\boldsymbol{x}$ follow independent standard normal distributions, $\Psi_{j}(\boldsymbol{x})$ in Eq. (14) could be written as a multi-dimensional Hermite polynomial:

$$
\Psi_{j}(\boldsymbol{x})=\prod_{j=1}^{N} \phi_{\alpha_{j}}\left(x_{j}\right), \quad \alpha_{j} \geq 0
$$

where $\phi_{a j}\left(x_{j}\right)$ is the one-dimensional Hermite polynomial. The unknown coefficients in Eqs. (14) and (15) could be determined by the regression approaches [23], e.g., Ordinary Least Squares (OLS) and Orthogonal Matching Pursuit (OMP) [54], among others. The PCE is founded on the regression approaches and a training set generated by MCS. More detailed information on the algorithm is available in [54]. The accuracy of the established PCE could be quantified by $R^{2}$ or leave-one-out coefficient. Herein, a test set is used to evaluate the $R^{2}$ of the proposed PCE:

$$
\begin{aligned}
& R^{2}=1-\frac{1 / N_{\text {test }} \sum_{i=1}^{N_{\text {test }}}\left[\Gamma\left(\boldsymbol{x}^{i}\right)-\Gamma^{P C E}\left(\boldsymbol{x}^{i}\right)\right]^{2}}{\operatorname{Var}(\Gamma)}, \\
& \operatorname{Var}(\Gamma)=\frac{1}{N_{\text {test }}} \sum_{i=1}^{N_{\text {test }}}\left[\Gamma\left(\boldsymbol{x}^{i}\right)-\frac{1}{N_{\text {test }}} \sum_{i=1}^{N_{\text {test }}} \Gamma\left(\boldsymbol{x}^{i}\right)\right]^{2}
\end{aligned}
$$

where $N_{\text {test }}$ is the size of the test set, and $\Gamma$ denotes the system response of MCS. Once the $R^{2}$ of PCE satisfies a given requirement, the PCE could be further used in SA.

\subsection{PCE-based global sensitivity analysis}

In this study, SA is conducted by estimating the Sobol' indices $S_{i 1, \ldots, i \mathrm{~s}}$, which could determine the contribution of random input variables (e.g., geometry and mechanical factors) to the variability of the system response [55]

$$
S_{i_{1}, \ldots, i_{s}}=D_{i_{1}, \ldots, i_{s}} / D
$$

where $D$ and $D_{i 1, \ldots, i s}$ are the total and partial variances of $g(x)$, which can be computed by Eq. (18) and (19), respectively.

$$
\begin{aligned}
& D=\operatorname{Var}[g(\boldsymbol{x})]=\int_{K^{N}} g^{2}(\boldsymbol{x}) d \boldsymbol{x}-g_{0}^{2}=\sum_{i=1}^{N} D_{i}+\sum_{1 \leq i<j \leq N} D_{i j}+\cdots+D_{1,2, \ldots, N} \\
& D_{i_{1}, \ldots, i_{s}}=\int_{K^{s}} g_{i_{1}, \ldots, i_{s}}^{2}\left(x_{i_{1}}, \ldots, x_{i_{s}}\right) d x_{i_{1}} \ldots . d x_{i_{s}}, 1 \leq i_{1}<\ldots<i_{s} \leq N, s=1, \ldots, N
\end{aligned}
$$


where $g_{0}$ is the expected value of $g(\boldsymbol{x})$ and the integral of each summand $g_{i 1 \ldots}$, is is equal to 0 .

$$
\begin{aligned}
& g_{0}=\int g(\boldsymbol{x}) d \boldsymbol{x}, g_{i}\left(x_{i}\right)=\int_{0}^{1} \ldots \int_{0}^{1} g(\boldsymbol{x}) d \boldsymbol{x}_{\sim i}-g_{0}, \\
& g_{i j}\left(x_{i}, x_{j}\right)=\int_{0}^{1} \ldots \int_{0}^{1} g(\boldsymbol{x}) d \boldsymbol{x}_{\sim(i j)}-g_{0}-g_{i}\left(x_{i}\right)-g_{j}\left(x_{j}\right)
\end{aligned}
$$

where the notation $\sim$ means the excluded variables and $\boldsymbol{x}_{\sim \mathrm{i}}$ denotes

$$
\mathbf{x}_{\sim i}=\left(x_{1}, \ldots, x_{i-1}, x_{i+1}, \ldots, x_{M}\right)
$$

According to Eq.(18), there exists

$$
\sum_{i=1}^{N} S_{i}+\sum_{1 \leq i<j \leq N} S_{i j}+\cdots+S_{1,2, \ldots, N}=1
$$

where $S_{\mathrm{i}}$ are the first-order indices only containing the influence of every single parameter. To consider the interaction effects of different parameters, total sensitivity indices $S_{T i}$ could be computed as [56]

$$
S_{T_{i}}=1-S_{\sim i}
$$

in which $S_{\sim i}$ is the sum of $S_{i 1, \ldots, i s}$ without $i$. In general, it is challenging to calculate Sobol' indices analytically, especially when using complex non-linear deterioration models such as the described in section 3. Then, MCS could usually be applied to compute Sobol' indices with a high computational cost. However, once PCE is set up, Sobol' indices could be easily obtained by the coefficients of PCE directly[53]. Based on the definition of Sobol index (Eq. (17)), $S_{i 1, \ldots, \text { is }}$ could be rewritten as [23]

$$
S_{i_{1}, \ldots, i_{s}}=\frac{\sum_{j \in I_{i_{1}, \ldots, i_{M}}} a_{j}^{2} E\left[\Psi_{j}^{2}\left(x_{i_{1}}, \ldots, x_{i_{M}}\right)\right]}{D_{P C}}, D_{P C}=\sum_{j=1}^{M-1} a_{j}^{2} E\left(\Psi_{j}^{2}\right)
$$

where $E(\cdot)$ denotes the expectation of $(\cdot)$. Moreover, $S_{i}$ and $S_{T i}$ could be calculated by

$$
S_{i}=\frac{\sum_{j \in I_{i}} a_{j}^{2} E\left[\Psi_{j}^{2}\left(x_{i_{1}}, \ldots, x_{i_{M}}\right)\right]}{\sum_{j=1}^{M-1} a_{j}^{2} E\left(\Psi_{j}^{2}\right)}, S_{T_{i}}=\frac{\sum_{j \in I_{i}^{*}} a_{j}^{2} E\left[\Psi_{j}^{2}\left(x_{i_{1}}, \ldots, x_{i_{M}}\right)\right]}{\sum_{j=1}^{M-1} a_{j}^{2} E\left(\Psi_{j}^{2}\right)}
$$

where $I_{i}^{*}$ denotes the set of all indices in the $i$-th element. 


\section{Illustrative examples}

\subsection{Study case description}

In this study, the developed finite element method (FEM) model is verified using the experimental data associated with 26-year old corroded and uncorroded reinforced concrete (RC) beams [30]. Accordingly, the corroded RC beam was subjected to a salt spray environment (35 g/l NaCl solution) and extern loading for six years. The uncorroded RC beam was under an environment with $50 \%$ relative humidity and $20^{\circ} \mathrm{C}$ temperature [30]. The beams were tested through three-point tests. More detailed information regarding the experimental studies can be found in [30]. Fig. 6a shows the schematic of the RC beam with a dimension of $3000 \mathrm{~mm} \times 150 \mathrm{~mm} \times 280 \mathrm{~mm}$ and a cover thickness of $10 \mathrm{~mm}$. The

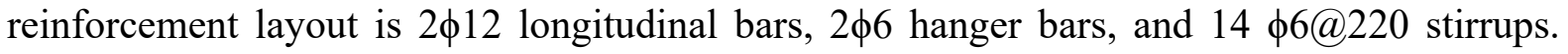
The beam is subjected to a concentrated load at its mid-span. Fig. $\mathbf{6 b}$ shows the FEM model of the RC beam with a mesh size of $15 \mathrm{~mm}$. In the $2 \mathrm{D}$ model of the beam, the concrete and reinforcement are discretized by 2D plane stress CQ16M and truss elements, respectively [26]. The geometry and materials parameters are summarized in Table $\mathbf{1}$ and Table $\mathbf{2}$, respectively. Other parameters related to the load step and equilibrium iteration procedure are listed in Table 3, where the load increments are 100 steps for the corroded case and 200 steps for the uncorroded case.

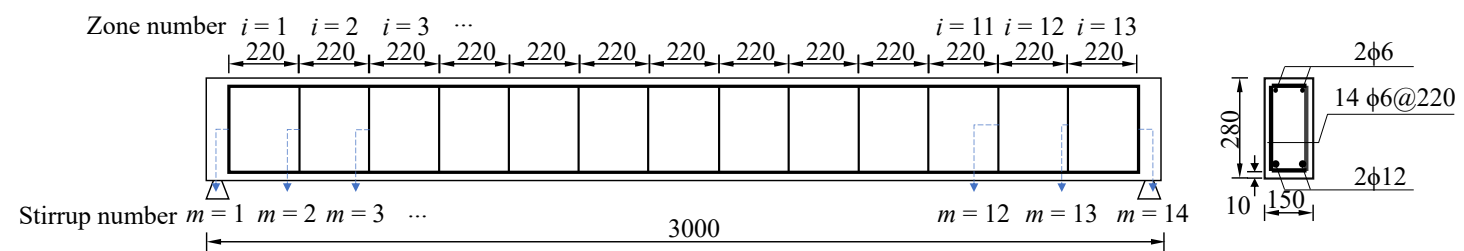

(a)

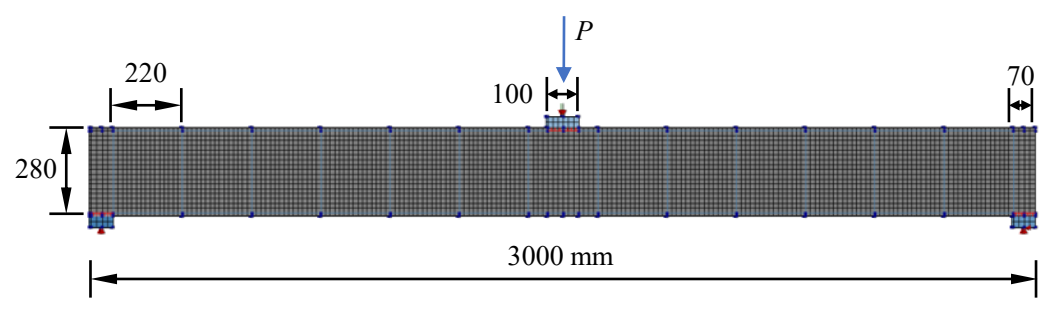

(b) 
Fig. 6. (a) Schematic of RC beam in [30] and (b) layout of FEM model of RC beam in DIANA $($ mesh size $=15 \mathrm{~mm})$

To account for spatial variability of corroded rebars, the beam is divided into 13 zones through the spacing of stirrups $(220 \mathrm{~mm})$, as shown in Fig. 6. Reinforcement corrosion is quantified by diameter loss [30], and all values of diameter loss are supposed to be zero for the uncorroded RC beam. Fig. 7 summarizes the distribution and maximum values of diameter loss of longitudinal bars at both sides of the beam and maximum diameter losses of stirrups at the left and right legs.

Comparing Fig. 7a with Fig. 7b, it seems that compression bars suffer more severe corrosion than tension bars. Zhu et al. [30] attributed this phenomenon to the poor quality of the interface between the compression bars and the concrete, which is related to the "top-bar" effect. The cross-sectional area of each zone is denoted as the sum of all minimum cross-sectional areas, e.g., $A_{t, i}, A_{\mathrm{c}, i}$, and $A_{\mathrm{sv}, m}$

$$
A_{t, i}=\sum_{j=1}^{n_{t}} A_{t, i, j}, A_{c, i}=\sum_{k=1}^{n_{c}} A_{c, i, k}, A_{s v, m}=\sum_{l=1}^{n_{s v}} A_{s v, m, l}
$$

where $A_{t, i, j}, A_{c, i, k}$ and $A_{\mathrm{sv}, m, l}$ refer to Eq. (1). For the uncorroded scenario, $A_{t, i}, A_{\mathrm{c}, i}$, and $A_{\mathrm{sv}, m}$ are $226.20 \mathrm{~mm}^{2}, 56.55 \mathrm{~mm}^{2}$, and $56.55 \mathrm{~mm}^{2}$, respectively, while for the corroded scenario, the relevant values are listed in Table 4.

Table 1 Parameters of model geometry

\begin{tabular}{lcccc}
\hline Geometry & Length $(\mathbf{m m})$ & Width $(\mathbf{m m})$ & Height $(\mathbf{m m})$ & Cover thickness $(\mathbf{m m})$ \\
\hline Beam & 3000 & 150 & 280 & 10 \\
Load plate & 100 & 150 & 35 & - \\
Support plate & 70 & 150 & 35 & - \\
\hline
\end{tabular}

Table 2 Parameters of material properties in [30]

\begin{tabular}{cc|cc}
\hline Concrete & & \multicolumn{2}{c}{ Reinforcement } \\
\hline$E_{\mathrm{c}}(\mathrm{MPa})$ & 25600 & $E_{\mathrm{s}}(\mathrm{MPa})$ & 273000 \\
Poisson ratio & 0.2 & Poisson ratio & 0.3 \\
Tensile strength $f_{\mathrm{t}}(\mathrm{MPa})$ & 1.88 & Yield strength $f_{\mathrm{y}}(\mathrm{MPa})$ & 600 \\
Compressive strength $f_{\mathrm{c}}(\mathrm{MPa})$ & 56 & Ultimate strength $f_{\mathrm{u}}(\mathrm{MPa})$ & 800 \\
\hline
\end{tabular}


Table 3 Parameters of load step and equilibrium iteration procedure

\begin{tabular}{|c|c|c|}
\hline Items & Option & Value \\
\hline \multicolumn{3}{|c|}{ Load } \\
\hline Preset point load & Y direction & $-0.1 \mathrm{~mm}$ \\
\hline Scale factor & - & 5 \\
\hline increments & - & $100(200)$ \\
\hline Step control & Arc length & Default \\
\hline \multicolumn{3}{|c|}{ Iterative method } \\
\hline Maximum number & - & 200 \\
\hline Method & Newton-Raphson & Default \\
\hline Speed up method & Line search & Default \\
\hline \multicolumn{3}{|c|}{ Convergence norm } \\
\hline Tolerance & Energy & 0.001 \\
\hline Tolerance & Force & 0.01 \\
\hline Abort criterion & Energy & 10000 \\
\hline Abort criterion & Force & 10000 \\
\hline
\end{tabular}

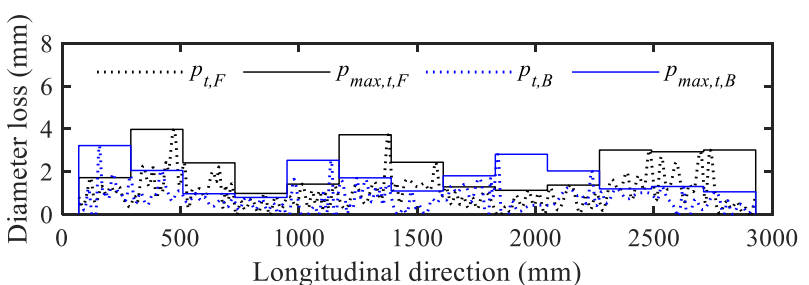

(a)

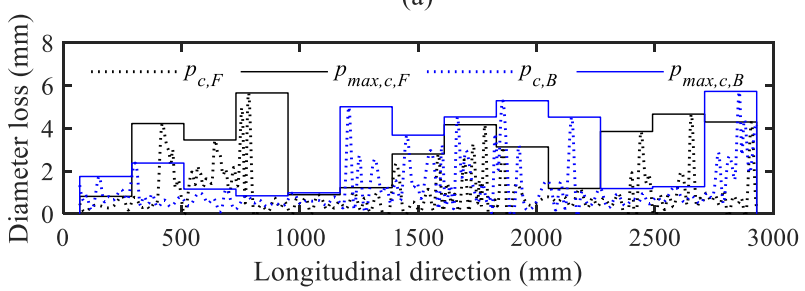

(b)

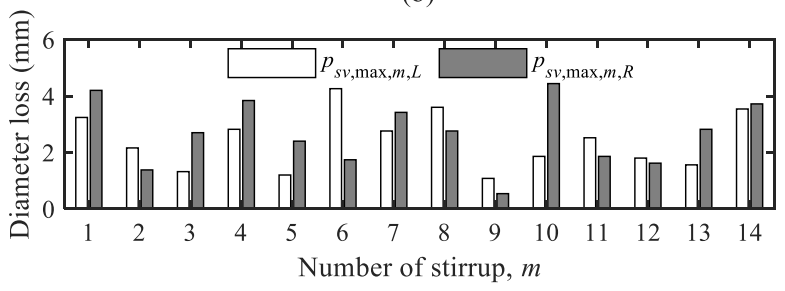

(c)

Fig. 7. (a) Comparison between the distribution of actual and maximum diameter loss for (a) tensile bars; (b) compressive bars; and (c) maximum diameter loss of stirrup bars

Note: $p_{t, \max , F}$ and $p_{t, \mathrm{max}, B}$ are the maximum diameter loss of tension bars in the front and back sides; $p_{c, \max , F}$ and $p_{c, \max , B}$ are the maximum diameter loss of compression bars in the front and back sides; and $p_{\text {svmax }, i, L}$ and $p_{s v m a x}, i, R$ are the maximum diameter loss of stirrup legs. 
Table 4 Cross-sectional area of each zone of corroded steel bar $\left(\mathrm{mm}^{2}\right)$

\begin{tabular}{|c|c|c|c|c|c|c|c|c|c|c|c|c|c|}
\hline$A_{\mathrm{sv}, 1}$ & $A_{\mathrm{sv}, 2}$ & $A_{\mathrm{sv}, \mathbf{3}}$ & $A_{\mathrm{sv}, 4}$ & $A_{\mathrm{sv}, 5}$ & $A_{\mathrm{sv}, \mathbf{6}}$ & $A_{\text {sv }, 7}$ & $\boldsymbol{A}_{\mathrm{sv}, \mathbf{8}}$ & $A_{\text {sv }, 9}$ & $A_{\mathrm{sv}, \mathbf{1 0}}$ & $A_{\mathrm{sv}, \mathbf{1 1}}$ & $A_{\mathrm{sv}, 12}$ & $A_{\mathrm{sv}, 13}$ & $A_{\mathrm{sv}, 14}$ \\
\hline 8.53 & 28.35 & 25.76 & 11.61 & 28.27 & 16.63 & 13.43 & 12.77 & 42.43 & 15.37 & 22.97 & 28.92 & 23.43 & 8.84 \\
\hline$A_{\mathbf{c}, 1}$ & $A_{\mathrm{c}, 2}$ & $A_{\mathrm{c}, 3}$ & $A_{\mathrm{c}, 4}$ & $A_{\mathrm{c}, 5}$ & $A_{\mathrm{c}, 6}$ & $A_{\mathrm{c}, 7}$ & $A_{\mathrm{c}, \mathbf{8}}$ & $A_{\mathrm{c}, 9}$ & $A_{\mathrm{c}, 10}$ & $A_{\mathrm{c}, 11}$ & $A_{\mathrm{c}, 12}$ & $A_{\mathrm{c}, 13}$ & \\
\hline 35.23 & 12.76 & 23.45 & 20.93 & 40.15 & 18.64 & 12.23 & 4.3 & 6.84 & 19.86 & 21.79 & 18.93 & 2.32 & \\
\hline$A_{\mathrm{t}, 1}$ & $A_{\mathrm{t}, 2}$ & $A_{\mathrm{t}, 3}$ & $A_{\mathrm{t}, 4}$ & $A_{\mathrm{t}, 5}$ & $A_{\mathrm{t}, \mathrm{6}}$ & $A_{\mathrm{t}, 7}$ & $A_{\mathrm{t}, 8}$ & $A_{\mathrm{t}, 9}$ & $\boldsymbol{A}_{\mathrm{t}, 10}$ & $A_{\mathrm{t}, 11}$ & $A_{\mathrm{t}, 12}$ & $\boldsymbol{A}_{\mathrm{t}, \mathbf{1 3}}$ & \\
\hline 143.76 & 128.4 & 168.01 & 194.2 & 158.57 & 137.09 & 165.42 & 171.95 & 159.31 & 166.95 & 155.37 & 154.62 & 157.69 & \\
\hline
\end{tabular}

Regarding the bond behaviors between steel bars and concrete, two scenarios are considered: 'perfect bond' and 'poor bond'. The former assumes no slip at the interface between reinforcement and concrete, and the latter considers the constitutive model of bond-slip given in Section 3.2.3.

\subsection{Comparison with experimental data}

\subsubsection{Comparisons of $P-\delta$ curves}

The calculation results of load $P$ versus the mid-span deflection $\delta$ are obtained and compared with experimental results, as indicated in Fig. 8. In general, it is observed that the $P-\delta$ curves of FEM are consistent with the experimental ones. The $P-\delta$ curves are similar at the initial stage but gradually become different with different corrosion conditions and bond assumptions. Besides, the upward slope of the $P-\delta$ curves for the FEM of the corroded scenario is close to that of the uncorroded scenario in the initial stage before concrete cracking in the tensile zone. The reason is that the corrosion-induced damage on concrete is not considered, but it does not influence the subsequent development of the $P-\delta$ curve after concrete cracking. Also, the bond condition could affect the stress and strain distribution of concrete and reinforcement and further affect the deflection at the beam mid-span.

Furthermore, the effect of the constitutive model of reinforcement on the $P-\delta$ curve is illustrated by employing the traditional bilinear constitutive model (only elastic and hardening phases) with or without corrosion-induced strain descent. The initial phase of the $P-\delta$ curve from the bilinear constitutive model agrees well with the other curves, but the 
critical loads such as $P_{\mathrm{y}}$ and $P_{\mathrm{u}}$ are higher, and the ultimate deformation is lower than other scenarios. Besides, $P_{\mathrm{u}}$ of the scenario without the strain descent is higher than other cases, and its ultimate deformation is slightly higher than the experimental result and the 'poor bond' scenario. For the uncorroded RC beam, the effect of the constitutive model of reinforcement on the $P-\delta$ curve appears to be insignificant, whereas it is larger for the corroded RC beam. Therefore, the bilinear constitutive model of reinforcement seems inappropriate, while the proposed constitutive model yields a $P-\delta$ curve that is closer to the experimental results.

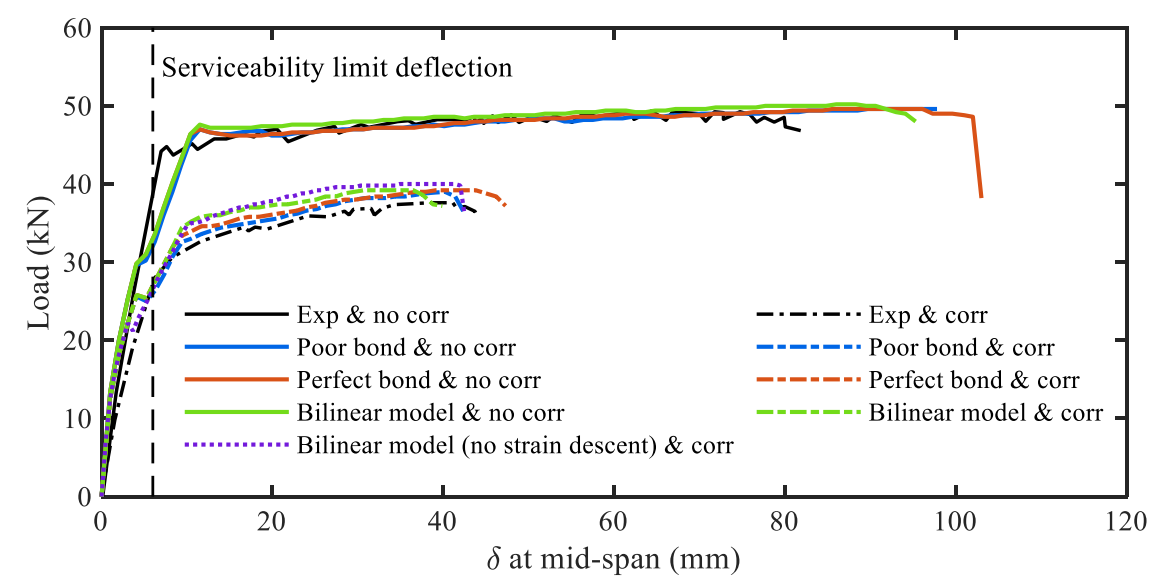

Fig. $8 P-\delta$ curves of FEM and experimental data

(Dotted black line denotes the serviceability limit deflection $L_{\mathrm{s}}=$ beam length / 500)

In the following analysis, $P_{\mathrm{s}}$ is the load for the serviceability limit deflection $\left(L_{\mathrm{s}}=\right.$ beam length/500); the yield load $P_{y}$ and deflection $\delta_{y}$ indicate the inflection point of the $P-\delta$ curve; and the ultimate load $P_{u}$ and deflection $\delta_{u}$ are related to the peak point of the $P-\delta$ curve. It is noted in Fig. 9 that $P_{y}, \delta_{y}, P_{u}$ and $\delta_{u}$ decrease with corrosion. These values are extracted from $P$ - $\delta$ curves and listed in Table 5. It can be noticed that $P_{u}$ and $P_{y}$ fit well within experimental and numerical results, but $P_{\mathrm{s}}$ does not fit well with the experiment for the uncorroded RC beam. Also, for the mid-span deflection, it can be noticed that $\delta_{y}$ and $\delta_{u}$ have a relatively large deviation, especially for $\delta_{y}$ of the uncorroded beam. The potential cause of this difference is that the employed constitutive model of concrete underestimates the stiffness of the actual concrete material, which further underestimates the rigidity of the beam. 
Concerning the scenario without corrosion, the values for 'poor bond' are close to that of 'perfect bond'. It demonstrates that it is acceptable to suppose 'perfect bond' for the uncorroded RC beam; although the values of $\delta_{y}$ of both 'poor bond' and 'perfect bond' do not fit well with the experiment. However, for the scenario with corrosion, it is noted that the condition of 'poor bond' fits better with the experiment than that of 'perfect bond' except for $P_{\mathrm{s}}$, which also indicates the 'poor bond' might cause the underestimation of beam stiffness.

Table 5 Comparisons of mechanical information of experimental data and FEM simulation

\begin{tabular}{cccccccccccc}
\hline & \multicolumn{2}{c}{$P_{s}$} & \multicolumn{2}{c}{$\delta_{y}$} & \multicolumn{2}{c}{$P_{y}$} & \multicolumn{3}{c}{$\delta_{u}$} & \multicolumn{3}{c}{$P_{u}$} \\
Case & $\begin{array}{c}\text { Value } \\
(\mathrm{kN})\end{array}$ & $\Delta_{\text {dev }}$ & $\begin{array}{c}\text { Value } \\
(\mathrm{mm})\end{array}$ & $\Delta_{\text {dev }}$ & $\begin{array}{c}\text { Value } \\
(\mathrm{kN})\end{array}$ & $\Delta_{\text {dev }}$ & $\begin{array}{c}\text { Value } \\
(\mathrm{mm})\end{array}$ & $\Delta_{\text {dev }}$ & $\begin{array}{c}\text { Value } \\
(\mathrm{kN})\end{array}$ & $\Delta_{\text {dev }}$ \\
\hline Exp \& no corr & 38.7 & - & 7.6 & - & 44 & - & 81.9 & - & 49.2 & - \\
Poor bond \& no corr & 32.1 & $17.2 \%$ & 11.5 & $51.3 \%$ & 46.31 & $5.3 \%$ & 97.8 & $18.4 \%$ & 49.6 & $0.8 \%$ \\
Perfect bond \& no corr & 33.0 & $14.8 \%$ & 11.5 & $51.3 \%$ & 47 & $6.8 \%$ & 102 & $23.5 \%$ & 49.6 & $0.8 \%$ \\
\hline Exp \& corr & 27.2 & - & 7.8 & - & 30 & - & 35.9 & - & 37.6 & - \\
Poor bond \& corr & 26.0 & $4.5 \%$ & 8.4 & $7.7 \%$ & 30.8 & $2.7 \%$ & 40.2 & $12.0 \%$ & 39 & $3.7 \%$ \\
Perfect bond \& corr & 27.0 & $0.8 \%$ & 8.4 & $7.7 \%$ & 32 & $6.7 \%$ & 43.8 & $22.0 \%$ & 39.2 & $4.3 \%$ \\
\hline
\end{tabular}

Note: $\Delta_{\text {dev }}$ denotes the $\mid 1$-computational value/experiment value $\mid \times 100 \%$; Exp denotes experimental value

\subsubsection{Comparisons of crack patterns}

Fig. 9 compares the crack patterns of RC beams when achieved the $P_{\mathrm{u}}$, i.e., ULS, under both experimental and numerical investigations. For the numerical simulation, cracks are generated only by loading. Therefore, numerical crack patterns are not reproducing horizontal cracks that are mainly due to corrosion (Fig. 9c and d).

Comparing uncorroded (Fig. 9a and b) with corroded (Fig. 9c and d) results, it could be noticed that the crack patterns, including the crack number, location, and spacing, change significantly due to the reinforcement corrosion. In the investigated example, the crack width of the uncorroded scenario is larger than that of the corroded scenario. The primary reason is that the crack width of ULS is related to the deformation capacity of the RC beam, e.g., $\delta_{\mathrm{u}}$. Both 'poor bond' and reinforcement corrosion could impair the $\delta_{\mathrm{u}}$ of the RC beam and reduce the crack width in the investigated case.

On the other hand, for the uncorroded RC beam, the crack pattern under 'perfect bond' case is symmetric (Fig. 9b), but it is asymmetric for 'poor bond'. This phenomenon may be 
due to the difference in strain between the tension bar and concrete in the tensile zone. Under the assumption of 'perfect bond', the strains of tension bars and concrete at the same node are supposed to be strictly consistent, so their strain and stress distribution are symmetrical on both sides. However, for 'poor bond', without such a strict condition, the strains at the same node might have some differences. To balance the force matrix and coordinate the element deformation, the stress and strain distribution on both sides of the beam could be different in the FEM calculation. Without considering the corrosion effect, this difference has a much more significant effect on the crack pattern. Besides, for the corroded RC beam, the crack pattern is also asymmetric (Figs. 9c and d), and its asymmetry seems much severe than that of the uncorroded RC beam (Figs. 9a and b). Comparing Fig. 9c with d, the bond condition does not influence much the crack pattern. Thus, being different from the uncorroded scenario, the asymmetry of the crack pattern is more due to corrosion non-uniformity than the bond condition.

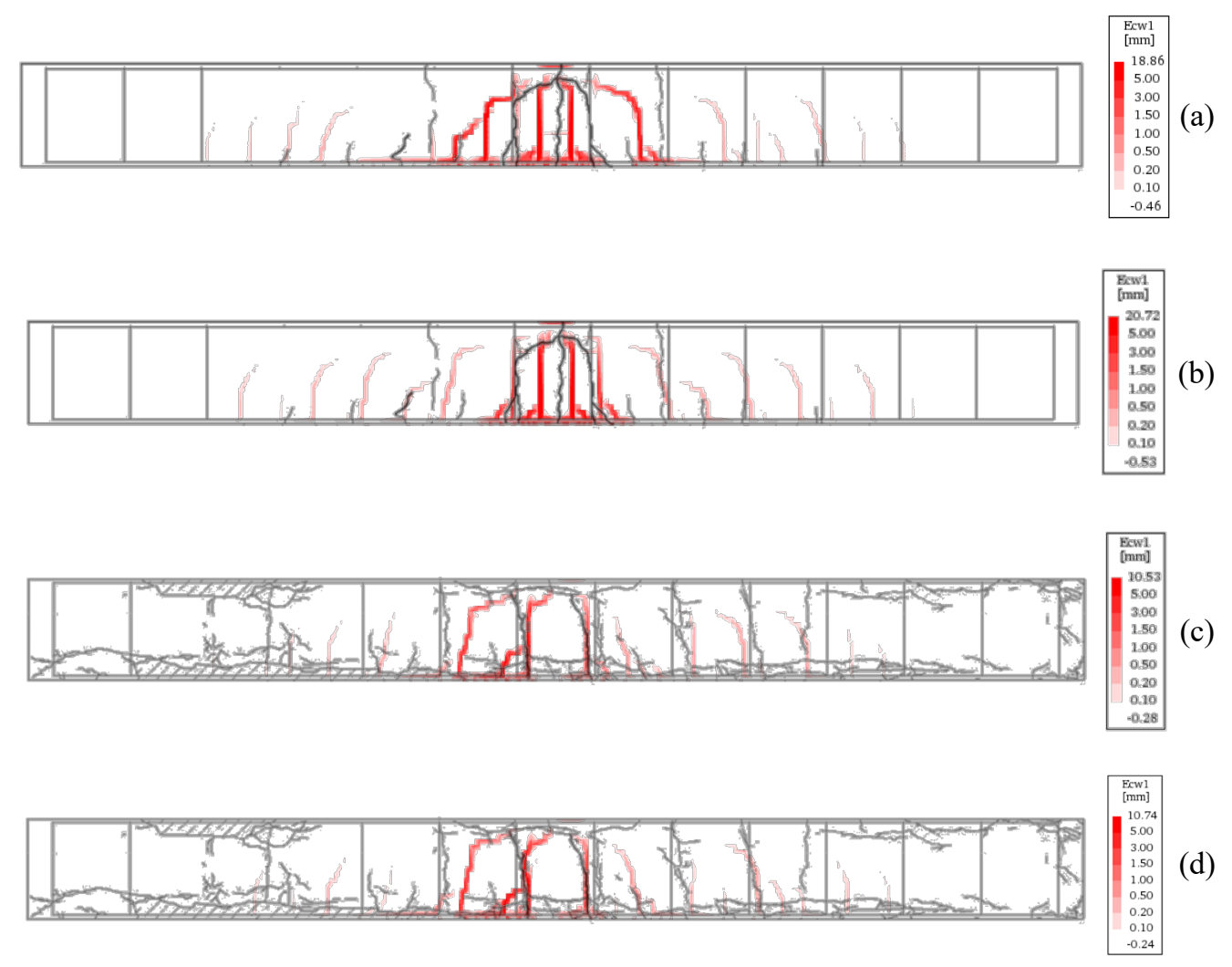

Fig. 9. Comparisons of crack patterns between experiment and simulation results of different scenarios: (a) poor bond \& no corr; (b) perfect bond \& no corr; (c) poor bond \& corr; and (d) perfect bond \& corr

(Ecw1 denotes the principal crack width; Black lines are experimental results [30], and red 
lines are simulation results)

\subsubsection{Effect of corrosion degree}

In order to investigate the effects of reinforcement corrosion on the simulation results, three corrosion scenarios are supposed:

(1) original corrosion degree $\left(\eta_{s}\right)$ in Fig. 7;

(2) 1.1 times the corrosion degree $\left(1.1 \eta_{s}\right)$ for all steel bar elements; and

(3) 1.25 times the corrosion degree $\left(1.25 \eta_{s}\right)$ for all steel bar.

Table 6 presents the results on the effect of bond condition for the above-mentioned corrosion degrees. It is noted that the bond condition slightly affects $P_{s}, P_{y}$, and $\delta_{y}$ and does not affect $\delta_{y}$ and $P_{\mathrm{u}}$ of the uncorroded RC beam, as the bond condition of the uncorroded RC beam is close to 'perfect bond'. For the corroded RC beam, the effect of bond condition on the deflection $\delta\left(\delta_{u}\right.$ and $\left.\delta_{y}\right)$ and load $P\left(P_{u}\right.$ and $\left.P_{y}\right)$ increases with the corrosion degree, while the effect of bond condition on $P_{\mathrm{s}}$ slightly decreases with corrosion degree. Since it is essential to consider the bond conditions for the mechanical evaluation of corroded RC beams, the constitutive model of bond-slip (Eqs. (12) and (13)) would be employed for the sensitivity and reliability analysis.

Table 6 Comparisons of mechanical information between 'perfect bond' and 'poor bond'

\begin{tabular}{|c|c|c|c|c|c|c|c|c|c|c|}
\hline \multirow[b]{2}{*}{ Case } & \multicolumn{2}{|c|}{$P_{s}$} & \multicolumn{2}{|c|}{$\delta_{y}$} & \multicolumn{2}{|c|}{$P_{y}$} & \multicolumn{2}{|c|}{$\delta_{u}$} & \multicolumn{2}{|c|}{$P_{u}$} \\
\hline & $\begin{array}{l}\text { Value } \\
(\mathrm{kN})\end{array}$ & $\Delta_{\text {dev }}$ & $\begin{array}{l}\text { Value } \\
(\mathrm{mm}) \\
\end{array}$ & $\Delta_{\text {dev }}$ & $\begin{array}{c}\text { Value } \\
(\mathrm{kN})\end{array}$ & $\Delta_{\mathrm{dev}}$ & $\begin{array}{l}\text { Value } \\
(\mathrm{mm})\end{array}$ & $\Delta_{\mathrm{dev}}$ & $\begin{array}{c}\text { Value } \\
(\mathrm{kN})\end{array}$ & $\Delta_{\text {dev }}$ \\
\hline Perfect bond \& no corr & 33.0 & - & 11.5 & - & 47 & - & 102 & - & 49.6 & - \\
\hline Poor bond \& no corr & 32.1 & $2.8 \%$ & 11.5 & $0.0 \%$ & 46.31 & $1.5 \%$ & 97.8 & $4.1 \%$ & 49.6 & $0.0 \%$ \\
\hline Perfect bond \& $\eta_{s}$ & 27.0 & - & 8.4 & - & 32 & - & 43.8 & - & 39.2 & - \\
\hline Poor bond \& $\eta_{s}$ & 26.0 & $3.7 \%$ & 8.4 & $0.0 \%$ & 30.8 & $3.8 \%$ & 40.2 & $8.2 \%$ & 39 & $0.5 \%$ \\
\hline Perfect bond \& $1.1 \eta_{s}$ & 26.2 & - & 9.0 & - & 30.6 & - & 38.2 & - & 36.4 & - \\
\hline Poor bond \& $1.1 \eta_{s}$ & 25.4 & $3.1 \%$ & 8.4 & $6.3 \%$ & 30 & $2.0 \%$ & 27.7 & $27.5 \%$ & 35.8 & $1.6 \%$ \\
\hline Perfect bond \& $1.25 \eta_{s}$ & 24.9 & - & 9.6 & - & 28.4 & - & 39.5 & - & 32.2 & - \\
\hline Poor bond \& $1.25 \eta_{s}$ & 24.2 & $2.8 \%$ & 7.9 & $17.9 \%$ & 29.2 & $2.8 \%$ & 24.3 & $38.5 \%$ & 31.8 & $1.2 \%$ \\
\hline
\end{tabular}

Note: $\Delta_{\text {dev }}$ denotes the $\mid 1-$ value of 'Poor bond'/ value of 'perfect bond' $\mid \times 100 \%$

In order to study the failure mode of a RC beam, the $\delta$ values of critical events until reaching $\delta_{u}$, are computed and drawn from the results of FEM simulations, as illustrated in Fig. 10. Seven critical failure events, such as concrete crushing, tension bar yielding, and 
breaking, among others., are investigated and plotted in Fig. 10, showing their sequence and corresponding failure modes. In Fig. 10, $\delta_{u}$ decreases rapidly with the corrosion degree, and the chronological order of events varies with the corrosion degrees and bond condition. Given no corrosion, tension bar yields first, then compression bar yields, followed by stirrup yielding, and finally, concrete crushes.

For the corroded RC beam with the original corrosion degree $\eta_{s}$, the tension bar breaks before the concrete crushing, which corresponds with the failure mode reported in [30]. Also, the event of stirrup bar yielding brings forward; for the 1.25 times of corrosion degree, the event of stirrup bar yielding even happens earlier than tension bar yielding. Comparing Fig. 10a with Fig. 10b, for the original corrosion degree case $\eta_{s}$, the stirrup bar breaks after $\delta_{u}$ under poor bond condition but before the tension bar under perfect bond condition. The probable cause is the poor bond between the tension bar and concrete, making it easier to concentrate stress on the tension bar and move its breaking sequence forward. However, after $1.1 \eta_{s}$, stirrup bars are severely corroded, leading to the stirrup bar breaking before the tension bar under both poor and perfect bond conditions. Thus, the failure mode of the RC beam might vary from ductile failure to brittle failure and even from flexural failure to shear failure with corrosion development. Besides, the bond condition might influence the failure mode of the corroded RC beam.

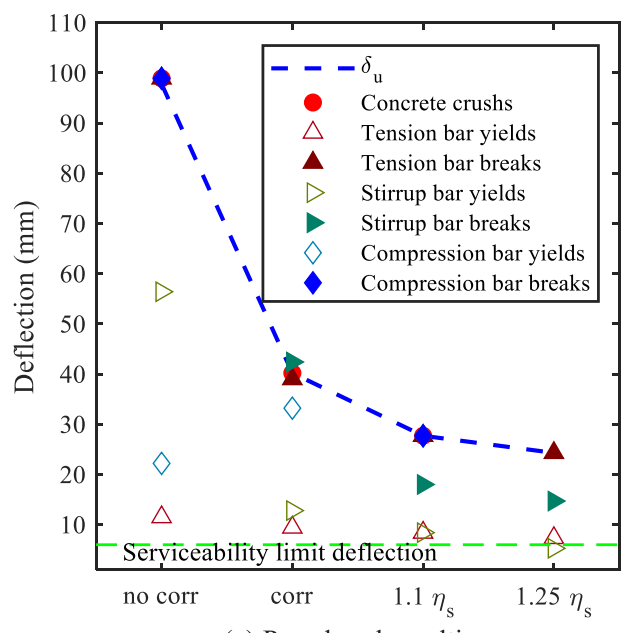

(a) Poor bond condtion

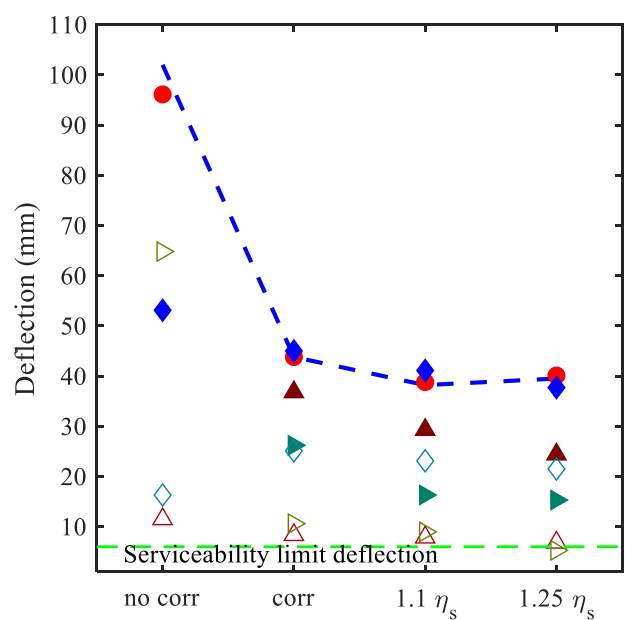

(b) Perfect bond condtion

Fig. 10. Deflection for various critical events 


\subsubsection{Spatial distribution of cracks and stresses}

The spatial distribution of concrete crack width and the stress of steel bars under ultimate load $P_{\mathrm{u}}$ are investigated in Fig. 11. Fig. 11a presents the distributions of crack width at the bottom of the beam. Due to the large deformation development of the uncorroded RC beam, its maximum crack width is larger than that of the corroded RC beam. From Fig. 11a, it could be noticed that the maximum crack width is not significantly influenced by the corrosion degree. However, the maximum crack width is affected by the bond condition because poor bond results in the deformation between concrete and longitudinal bar and simultaneously increase the crack width of concrete. Therefore, ignoring the bond strength loss might underestimate the crack width evaluation of the RC beam.

On the other hand, Fig. 11b shows the stress distribution of longitudinal bars under $P_{u}$, in which the stresses of the longitudinal bar within the location from $1,170 \mathrm{~mm}$ to $1,390 \mathrm{~mm}$ reach the ultimate stress. This result is expected as this zone is mostly affected by the corrosion of compressive and tensile bars (Fig. 7). Excepting this critical zone, the stress distribution under load $P_{\mathrm{u}}$ slightly decreases with the corrosion degree.

In addition, Fig. 11c presents the maximum stress within each stirrup bar under $P_{u}$, in which only the stirrup bar in the mid-span of the corroded RC beam reaches the ultimate stress. It is noted that the bond condition influences the stress distribution of stirrup bars. As corrosion progresses, more stirrup bars approach ultimate strength. For $1.25 \eta_{s}$, the perfect bond concentrates the stress on the stirrup bars in the mid-span of the beam $(m=6,7$, and 8$)$, but poor bond distributes the stress of stirrup bars discretely $(m=4,7$, and 8$)$. 


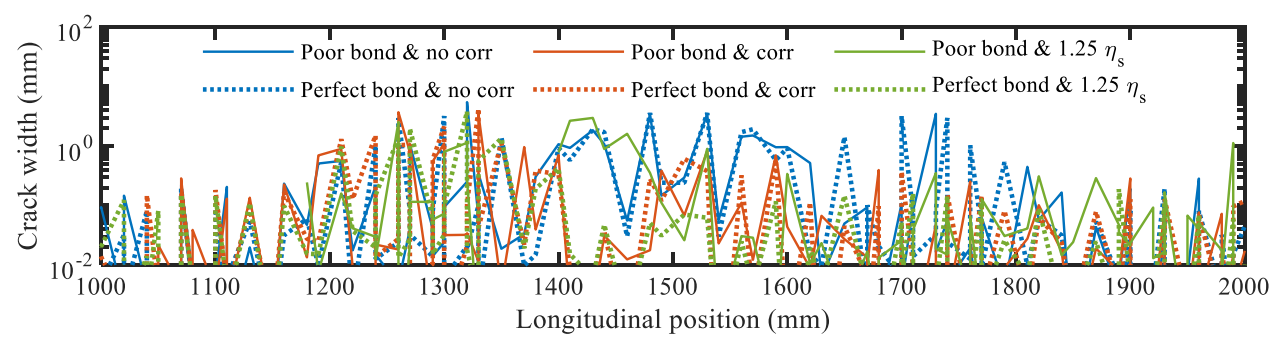

(a)

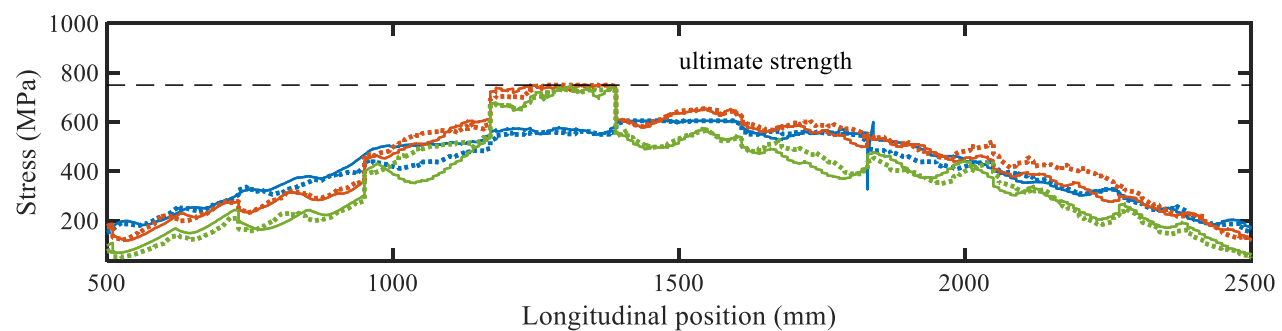

(b)

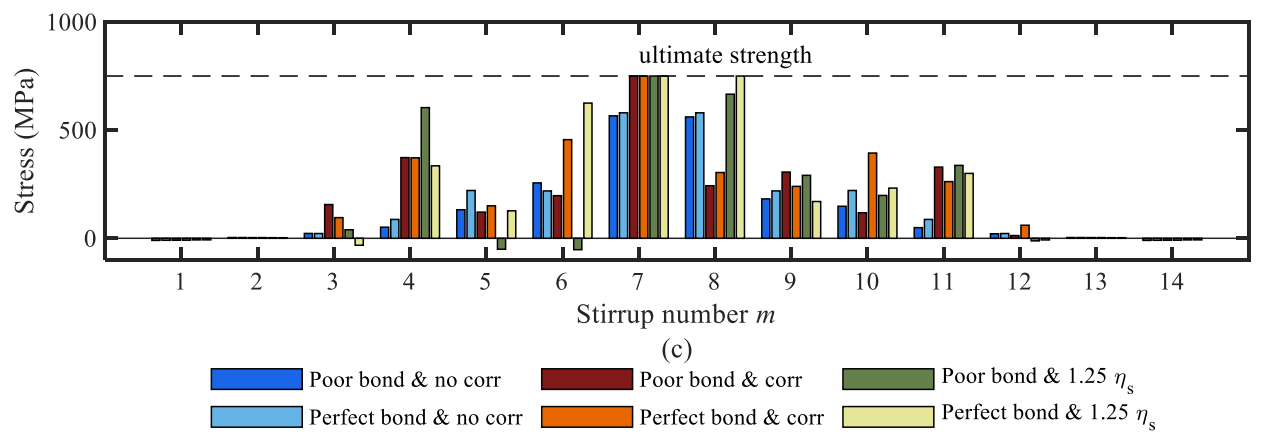

Fig. 11. (a) Crack width distribution at beam bottom; (b) stress distribution of longitudinal bars; and (c) stress distribution of stirrup bars under $P_{u}$

Due to the spatial effects of non-uniform corrosion, the cracking pattern and stress of steel bars are non-uniformly distributed along the $\mathrm{RC}$ beam. Corrosion degree mainly influences the deflection and load capacity of the RC beam, the distribution of concrete cracks, and the stress of steel bars. Also, the bond condition affects the distribution of crack and steel bar stress and the deflection and load capacity of corroded RC beam. Thus, realistic modeling of deterioration processes in corroded rebars that considers the spatial variability of corrosion and the bond strength loss of both longitudinal bars and stirrups is paramount for comprehensive condition, lifetime assessment, and failure analysis.

\subsection{PCE-based global sensitivity analysis of RC beams}

\subsubsection{Problem description}

Based on the geometry model and loading mode described in Sections 5.1 and 5.2, the uncertainties of geometry parameters $(L, b, h$, and $c$ of the beam, and cross-sectional area of 
corroded steel bar) and mechanical parameters $\left(f_{\mathrm{y}}, f_{\mathrm{c}}\right.$, and $\left.E_{\mathrm{s}}\right)$ on the serviceability and ultimate capacity are investigated. One deterministic FEM analysis of the RC beam costs around 10 to 15 minutes by using a PC (CPU: Intel ${ }^{\circledR}$ Core ${ }^{\mathrm{TM}}$ i5-8400, 6 Cores; Memory: 16 GB). Thus, MCS, which need a large scale of computations, are costly and not feasible.

In this subsection, a surrogate model based on polynomial chaos expansion (PCE) is established. The input variables are given in the following random vector $\boldsymbol{X}=\left[L, b, h, c, f_{y}, f_{c}\right.$, $\left.E_{\mathrm{s}}, \mathbf{A}_{\mathrm{sv}}, \mathbf{A}_{\mathrm{t}}, \mathbf{A}_{\mathrm{c}}\right]$, where $\mathbf{A}_{\mathrm{sv}}, \mathbf{A}_{\mathrm{t}}$, and $\mathbf{A}_{\mathrm{c}}$ are the vectors of minimum cross-sectional areas of stirrup bars $\left[A_{s v, 1}, A_{s v, 2}, \ldots, A_{s v, n+1}\right]$, tension bars $\left[A_{t, 1}, A_{t, 2}, \ldots, A_{t, n}\right]$, and compression bars $\left[A_{c, 1}\right.$, $\left.A_{c, 2}, \ldots, A_{c, n}\right]$, respectively. Probability distributions of geometry and mechanical parameters are listed in Table 7 and those for the cross-sectional area of corroded steel bars are based on the distribution of factor $R$ (Eqs.(6) and (7)). In this study, all random variables are supposed to be independent.

Table 7 Distribution type and values of the parameters

\begin{tabular}{cccc|cccc}
\hline Parameter & Distribution & Mean & COV & Parameter & Distribution & Mean & COV \\
\hline$L(\mathrm{~mm})$ & Normal & 3000 & $0.01[57]$ & $f_{\mathrm{y}}(\mathrm{MPa})$ & Lognormal & 600 & $0.10[58]$ \\
$b(\mathrm{~mm})$ & Normal & 150 & $0.01[57]$ & $f_{\mathrm{c}}(\mathrm{MPa})$ & Normal & 42 & $0.15[59]$ \\
$h(\mathrm{~mm})$ & Normal & 280 & $0.01[57]$ & $E_{\mathrm{s}}(\mathrm{MPa})$ & Normal & 200000 & $0.02[60]$ \\
$c(\mathrm{~mm})$ & Lognormal & 10 & $0.10[58]$ & & & & \\
\hline
\end{tabular}

Note: all Normal distributions are truncated at 0.

The main outputs are the external load $P$ and deflection $\delta$ under different limit states, including serviceability limit state (SLS) and ultimate limit state (ULS). In general, the SLS can be expressed through crack width and deflection. In this case, three levels of SLSs are investigated: SLS1 (crack width $=0.05 \mathrm{~mm}[61]), \operatorname{SLS} 2(\delta=L / 500$ [62]), and SLS3 (crack width $=1 \mathrm{~mm}[63])$, and three corresponding loads are denoted as $P_{\mathrm{s} 1}, P_{\mathrm{s} 2}$, and $P_{\mathrm{s} 3}$. For the ULS, the ultimate load $P_{\mathrm{u}}$ of the $P-\delta$ curve is collected, and the corresponding failure mode can be determined according to the occurrence order of critical events, i.e., the increasing sequence of $\delta$ under critical events. Based on different corrosion current density $i_{\text {corr }}$ and average corrosion degree of steel bars $\eta_{\text {ave, }} 16$ scenarios are investigated, as shown in Table 8. For each scenario of $i_{\text {corr }}$ and $\eta_{\text {ave }}$ (Table 8), the cross-sectional area distribution is calculated by Eqs. (5) and (26). 
Table $8 i_{\text {corr }}$ and $\eta_{\text {ave }}$ of different cases

\begin{tabular}{|c|c|c|c|c|c|c|c|c|c|c|c|}
\hline No & $\begin{array}{c}i_{\text {corr }} \\
\left(\mu \mathrm{A} / \mathrm{cm}^{2}\right)\end{array}$ & $\eta_{\text {ave }}$ & No & $\begin{array}{c}i_{\text {corr }} \\
\left(\mu \mathrm{A} / \mathrm{cm}^{2}\right)\end{array}$ & $\eta_{\text {ave }}$ & No & $\begin{array}{c}i_{\text {corr }} \\
\left(\mu \mathrm{A} / \mathrm{cm}^{2}\right)\end{array}$ & $\eta_{\text {ave }}$ & No & $\begin{array}{c}i_{\text {corr }} \\
\left(\mu \mathrm{A} / \mathrm{cm}^{2}\right)\end{array}$ & $\eta_{\text {ave }}$ \\
\hline 1 & \multirow{4}{*}{0.1} & 0 & 5 & \multirow{4}{*}{0.5} & 0 & 9 & \multirow{4}{*}{1} & 0 & 13 & \multirow{4}{*}{3} & 0 \\
\hline 2 & & $10 \%$ & 6 & & $10 \%$ & 10 & & $10 \%$ & 14 & & $10 \%$ \\
\hline 3 & & $30 \%$ & 7 & & $30 \%$ & 11 & & $30 \%$ & 15 & & $30 \%$ \\
\hline 4 & & $50 \%$ & 8 & & $50 \%$ & 12 & & $50 \%$ & 16 & & $50 \%$ \\
\hline
\end{tabular}

\subsubsection{Comparison between PCE and numerical simulations}

For each case in Table 8, Monte Carlo simulation (MCS) is performed to create 500 samples; relevant details such as $P-\delta$ curves, reinforcement stress, and concrete strain in the compression zone are obtained for further analysis. Taking the $i_{\text {corr }}$ of $1 \mu \mathrm{A} / \mathrm{cm}^{2}$ and $\eta_{\text {ave }}$ of $10 \%$ as one example, Fig. 12a compares the simulated $P-\delta$ curves with the experimental $P-\delta$ curve of corroded RC beam. It can be found that the simulation results are close at the elastic stage, but their variations increase significantly after the yielding stage. In addition, Fig. 12b shows the histogram of ultimate load $P_{\mathrm{u}}$ from simulated results, and its probability density curve is obtained by the kernel density estimation [64], as well as the mean, maximum and minimum value of $P$ at different $\delta$. Also, the experimental $P_{\mathrm{u}}, 2.5 \%$, and $97.5 \%$ quantile values of simulated $P_{\mathrm{u}}$ and their corresponding PDF values are marked in Fig. 12b. The experimental $P_{\mathrm{u}}$ is within the $95 \%$ confidence interval of simulated $P_{\mathrm{u}}$ and close to the simulated peak value.

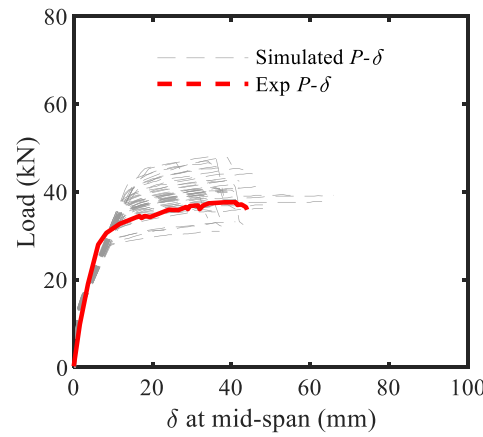

(a)

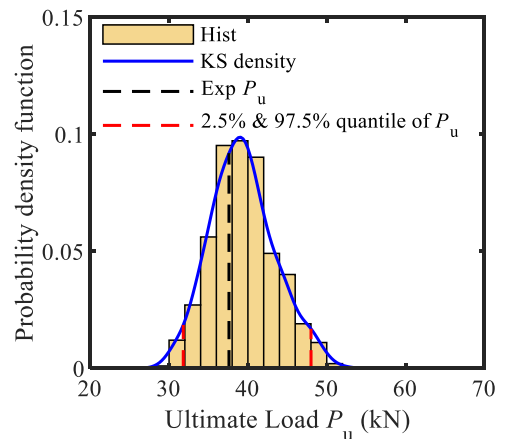

(b)

Fig. 12. (a) PDF contour of simulated $P-\delta$ curves and experimental $P-\delta$ curves; (b) Histogram of simulated ultimate load $P_{u}$ and experimental ultimate load $P_{u}$ 
Furthermore, 400 numerical samples are used to establish the PCE (training set), and the other 100 are collected to test the developed PCE (testing set). As shown in Fig. 13, the predicted PCE values of $P_{\mathrm{s} 1}, P_{\mathrm{s} 2}, P_{\mathrm{s} 3}$, and $P_{\mathrm{u}}$ are compared with the actual values by using $i_{\text {corr }}$ $=0.5 \mu \mathrm{A} / \mathrm{cm}^{2}$ as an example. In Fig. 13, the $R^{2}$ of the PCEs for $P_{\mathrm{s} 1}$ and $P_{\mathrm{s} 2}$ range from 0.73 to 0.99, while the $R^{2}$ of the PCEs for $P_{\mathrm{s} 3}$ and $P_{\mathrm{u}}$ range from 0.84 to 0.96 , in which the $R^{2}$ of most scenarios are higher than 0.8 .

On the other hand, regarding the minimum and maximum $i_{\text {corr }}\left(0.1\right.$ and $\left.3 \mu \mathrm{A} / \mathrm{cm}^{2}\right)$, Fig. 14 compares the predictions and actual values of $P_{\mathrm{s} 1}$ and $P_{\mathrm{u}}$. In Fig. 14, it can be found that $i_{\text {corr }}$ does not influence $P_{\mathrm{s} 1}$ and $P_{\mathrm{u}}$ in the case of $\eta_{\text {ave }}=0$, but $i_{\text {corr }}$ affects $P_{\mathrm{s} 1}$ and $P_{\mathrm{u}}$ with the degree of corrosion. Besides, the $R^{2}$ values of $P_{\mathrm{s} 1}$ and $P_{\mathrm{u}}$ are higher than 0.73 and are not widely influenced by $i_{\text {corr. }}$ The estimated values of $R^{2}$ as well as the ability of the PCE approximations to deal with different corrosion scenarios and limit state functions demonstrate that this approximation could be used for lifetime assessment and sensitivity analysis (SA).

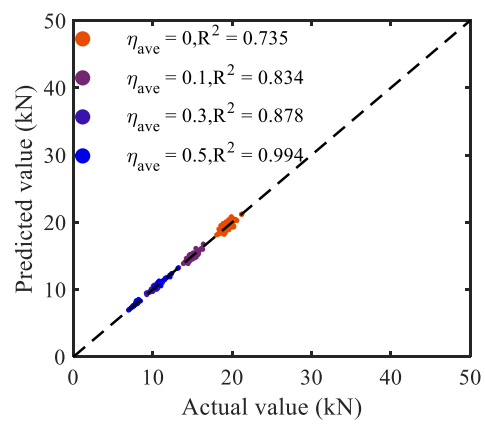

(a)

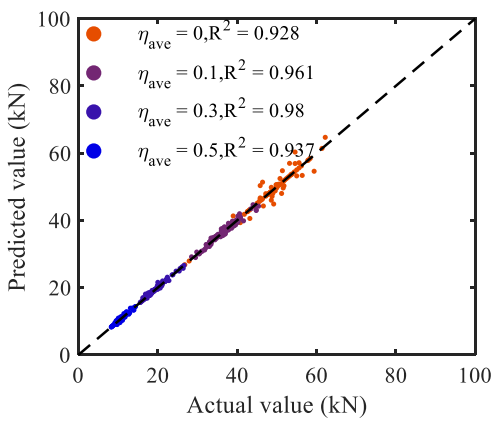

(c)

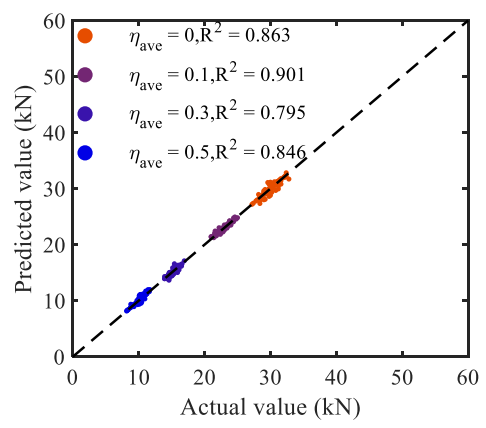

(b)

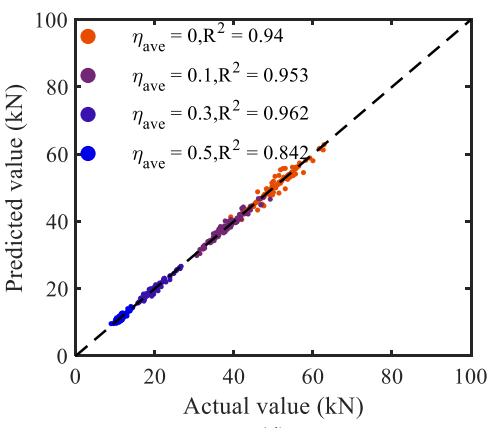

(d)

Fig. 13. Comparison between the predictions and actual values under $i_{\text {corr }}=0.5 \mu \mathrm{A} / \mathrm{cm}^{2}$ : (a) $P_{\mathrm{s} 1},(\mathrm{~b}) P_{\mathrm{s} 2}$, (c) $P_{\mathrm{s} 3}$, and (d) $P_{\mathrm{u}}$ 


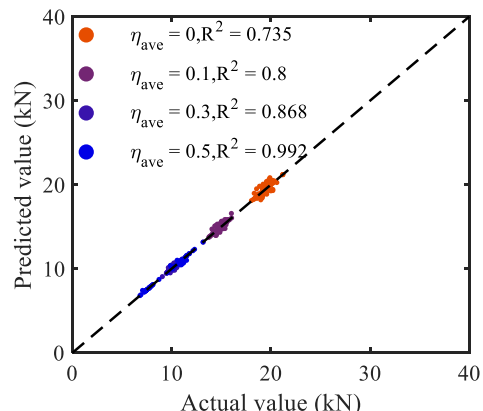

(a)

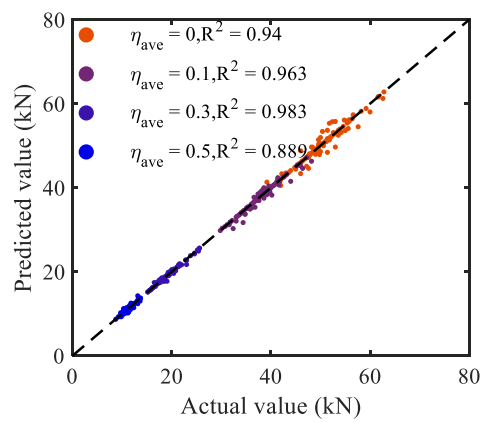

(c)

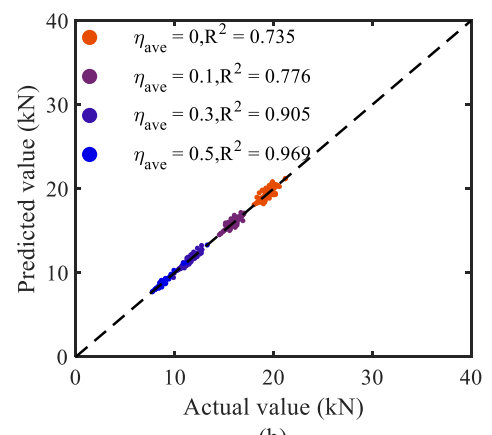

(b)

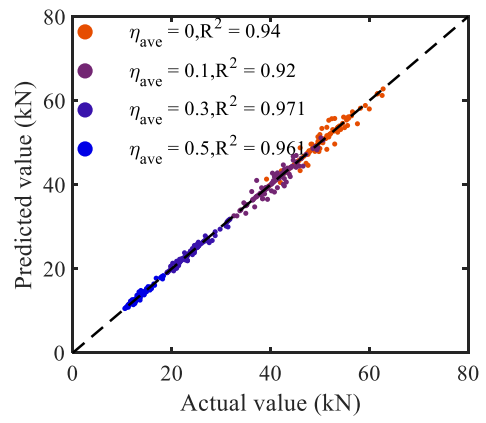

(d)

Fig. 14. Comparison between the predictions and actual values of $P_{\mathrm{s} 1}$ and $P_{\mathrm{u}}$ :

(a) $P_{\mathrm{s} 1}, i_{\text {corr }}=0.1 \mu \mathrm{A} / \mathrm{cm}^{2}$, (b) $P_{\mathrm{s} 1}, i_{\text {corr }}=3 \mu \mathrm{A} / \mathrm{cm}^{2}$,

(c) $P_{\mathrm{u}}, i_{\text {corr }}=0.1 \mu \mathrm{A} / \mathrm{cm}^{2}$, and (d) $P_{\mathrm{u}}, i_{\text {corr }}=3 \mu \mathrm{A} / \mathrm{cm}^{2}$

The random distribution of the target physical variables could be easily obtained through a MCS with $10^{6}$ simulations from the PCE model. For instance, Fig. 15 depicts the PDF of the original simulations and PCE for $i_{\text {corr }}=3 \mu \mathrm{A} / \mathrm{cm}^{2}$. As seen in Fig. 15, the PDFs of PCE obtained by the training set fit well with the discrete PDF of 500 simulations. These results are useful for computing the reliability under different limit states of a corroded beam subjected to a given external load and different corrosion degrees. 


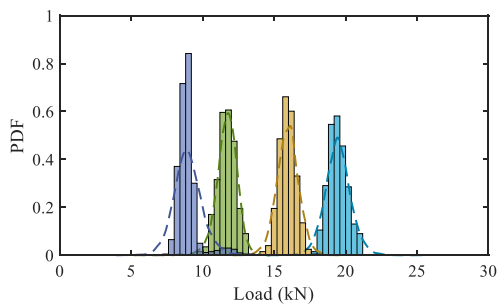

(a)

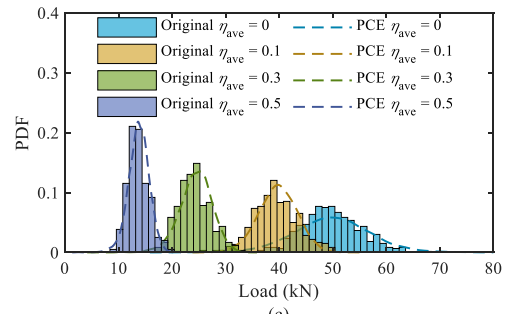

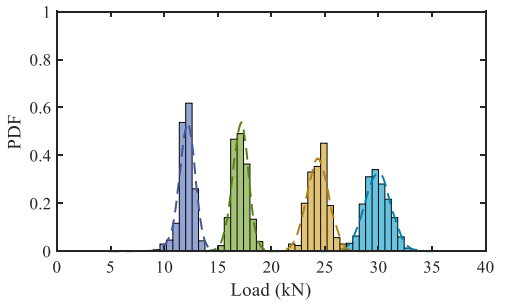

(b)

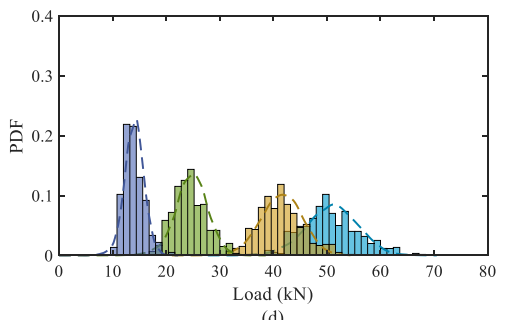

Fig. 15. Comparison between PDF of actual and PCE values for $i_{\text {corr }}=3 \mu \mathrm{A} / \mathrm{cm}^{2}$ : (a) $P_{\mathrm{s} 1}$, (b)

$$
P_{\mathrm{s} 2},(\mathrm{c}) P_{\mathrm{s} 3} \text {, and (d) } P_{\mathrm{u}}
$$

\subsubsection{Failure probability with respect to different failure modes}

The comprehensive numerical model allows establishing the occurrence of critical events for different corrosion levels, as illustrated in Fig. 10. PCE enables the development of surrogate models for the external loads associated with the three failure modes, i.e., stirrup breaking, longitudinal bar breaking, and concrete crushing. Given the input information, the values of three loads can be evaluated and compared to determine the failure mode by the method described in Section 5.2.3. In addition, by combining with MCS, these surrogate models can be used to evaluate the probability of occurrence of these three failure modes $P_{f 1}$ (stirrup breaking), $P_{f 2}$ (tension bar breaking), and $P_{f 3}$ (concrete crushing).

Based on the failure events for each mode, Fig. 16 illustrates the contribution of each failure mode for different corrosion scenarios. It is found that the failure mode of an uncorroded RC beam is dominated by concrete crushing. Besides, the failure mode of a corroded RC beam varies with the corrosion degree and corrosion rate, which could be summarized as follows:

(1) For $\eta_{\text {ave }}=10 \%$, the failure mode is dominated by tension bar breaking $\left(P_{f 2}=53 \%\right.$ to $72 \%$ ). Besides, $P_{f 2}$ decreases with $i_{\text {corr }}$, while $P_{f 1}$ increases with $i_{\text {corr }}$, and $P_{f 3}$ remains basically unchanged; 
(2) For $\eta_{\text {ave }}=30 \%$, the failure mode is still dominated by tension bar breaking $\left(P_{f 2}=86 \%\right.$ to $89 \%$ ) is much higher than the scenario of $\eta_{\mathrm{s}}=10 \%$. The values of $P_{f 1}, P_{f 2}$, and $P_{f 3}$ are literally unchanged with $i_{\text {corr; }}$, and

(3) For $\eta_{\text {ave }}=50 \%, P_{f 2}$ is still the largest $\left(P_{f 2}=66 \%\right.$ to $\left.82 \%\right)$, but $P_{f 1}$ becomes higher than the scenario of $\eta_{\text {ave }}=30 \%$. Meanwhile, $P_{f 2}$ increases with $i_{\text {corr, }}$, while $P_{f 1}$ decreases with $i_{\text {corr, }}$ and $P_{f_{3}}$ changes a few.

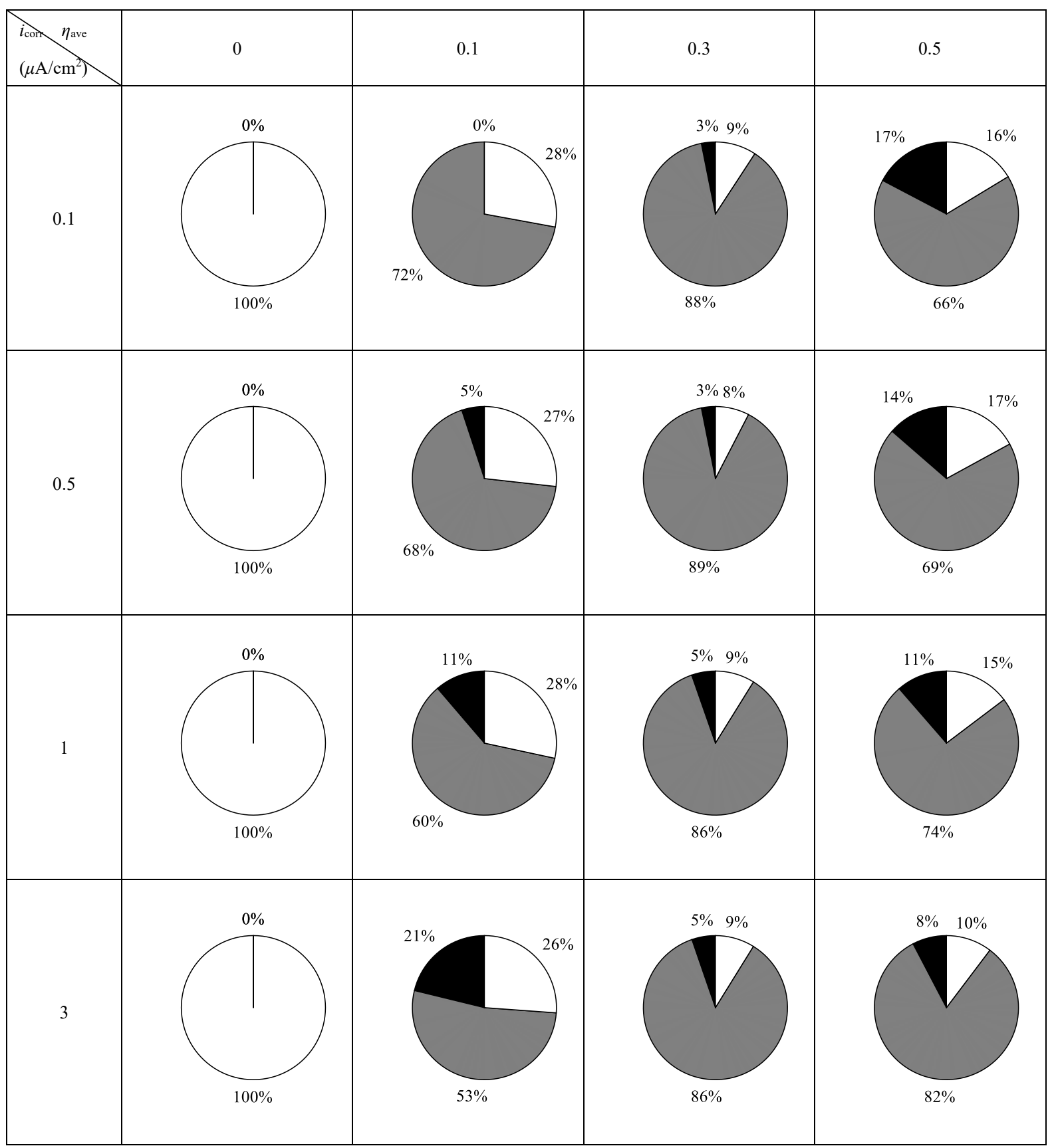


Fig. 16. Contribution of failure modes under different $i_{\text {corr }}$ and $\eta_{\text {ave }}$

In general, for the corroded RC beam, the possible failure mode is tension bar breaking, which is consistent with the failure mode of experimental results in [30]. Also, the deterministic analysis in Section 5.2.3 proves that stirrup breaking may happen with corrosion development. Furthermore, considering the uncertainties of geometry and mechanical parameters, it can be found that the probability of stirrup breaking increases with corrosion degree under a low corrosion rate, while the probability of stirrup breaking decreases with corrosion degree under a high corrosion rate. Thus, compared with experimental study and deterministic analysis, more comprehensive knowledge of failure analysis could be conducted through the PCE-based probabilistic analysis.

\subsubsection{Global sensitivity analysis}

By performing $\mathrm{SA}$, the total sensitivity factors $S_{\mathrm{Ti}}$ of all components of vector $\mathbf{X}$ are estimated. With $i_{\text {corr }}=3 \mu \mathrm{A} / \mathrm{cm}^{2}$, the highest five $S_{\text {Ti }}$ are presented in Table 9, which shows that the relationship between $S_{\mathrm{Ti}}$ versus $\eta_{\text {ave }}$ differs among different limit states. For $P_{\mathrm{s} 1}$, the $S_{\mathrm{Ti}}$ of $\mathbf{A}_{\mathbf{s v}}, \mathbf{A}_{\mathbf{t}}$, and $\mathbf{A}_{\mathbf{c}}$ have the most significant effect, and its order of importance depends on $\eta_{\text {ave. }} \mathbf{A}_{\mathrm{t}}$ has the larger $S_{\mathrm{Ti}}$ values when $\eta_{\text {ave }} \geqslant 0.1$. Geometrical and strength parameters had minor importance for $P_{\mathrm{s} 1}$. For $P_{\mathrm{s} 2}$, the $S_{\mathrm{Ti}}$ of $f_{\mathrm{c}}$ and geometrical parameters are the largest when $\eta_{\text {ave }}=0$ to 0.1 , but that of $\mathbf{A}_{\mathrm{t}}$ becomes the largest when $\eta_{\mathrm{ave}}=0.5$. For $P_{\mathrm{s} 3}$, the $S_{\mathrm{Ti}}$ of $\mathbf{A}_{\mathrm{sv}}$, $\mathbf{A}_{\mathbf{t}}$, and $\mathbf{A}_{\mathbf{c}}$ are the most critical ones when $\eta_{\mathrm{ave}}=0$, while the $S_{\mathrm{Ti}}$ of $f_{\mathrm{y}}$ and $\mathbf{A}_{\mathrm{t}}$ rise significantly when $\eta_{\text {ave }} \geqslant 0.1$. Moreover, for $P_{\mathrm{u}}$, the $S_{\mathrm{Ti}}$ of $f_{\mathrm{y}}$ is the largest when $\eta_{\mathrm{ave}} \leqslant 0.1$, but that of $\mathbf{A}_{\mathrm{t}}$ exceeds $f_{\mathrm{y}}$ and becomes the largest one when $\eta_{\mathrm{ave}} \geqslant 0.3$. In addition, the $\mathrm{S}_{\mathrm{Ti}}$ of $\mathbf{A}_{\mathrm{sv}}$ decreases with $\eta_{\text {ave. }}$ Such a result is consistent with the analysis of Section 5.3.3 where it was found that at a high corrosion rate, the contribution and failure probability of tension bars increase with corrosion development. In summary, for this level of corrosion rate, the remaining steel areas are the main influencing parameters for the appearance of hairline cracks in the concrete $\left(P_{\mathrm{s} 1}\right)$. For reaching a larger crack width $\left(P_{\mathrm{s} 3}\right)$, the strength parameters also become essential. Concerning deflection $\left(P_{\mathrm{s} 2}\right)$, the strength and geometry parameters 
have a more significant role. Moreover, for failure $\left(P_{\mathrm{u}}\right)$, a combination of strength and remaining steel areas is critical.

Table 9 Comparisons of $S_{\mathrm{Ti}}$ for various limit states under $i_{\text {corr }}=3 \mu \mathrm{A} / \mathrm{cm}^{2}$

\begin{tabular}{|c|c|c|c|c|c|c|c|c|c|c|c|}
\hline \multirow{3}{*}{$\begin{array}{c}\text { Parameter } \\
S_{\mathrm{Ti}}\end{array}$} & \multirow{3}{*}{$\frac{\eta_{\text {ave }}}{0}$} & \multicolumn{5}{|c|}{$P_{\mathrm{s} 1}($ crack width $=0.05 \mathrm{~mm})$} & \multicolumn{5}{|c|}{$P_{\mathrm{s} 2}(\delta=L / 500)$} \\
\hline & & $\mathbf{A}_{\mathrm{c}}$ & $\mathbf{A}_{\mathrm{t}}$ & $\mathbf{A}_{\mathrm{sv}}$ & $L$ & $f_{\mathrm{c}}$ & $f_{\mathrm{c}}$ & $L$ & $h$ & $\mathbf{A}_{\mathrm{sv}}$ & $E_{\mathrm{s}}$ \\
\hline & & 0.495 & 0.482 & 0.384 & 0.122 & 0.064 & 0.263 & 0.219 & 0.197 & 0.135 & 0.133 \\
\hline Parameter & 01 & $\mathbf{A}_{\mathrm{t}}$ & $\mathbf{A}_{\mathrm{sv}}$ & $\mathbf{A}_{\mathrm{c}}$ & $f_{\mathrm{c}}$ & $E_{\mathrm{s}}$ & $f_{\mathrm{c}}$ & $L$ & $h$ & $\mathbf{A}_{\mathrm{t}}$ & $E_{\mathrm{s}}$ \\
\hline$S_{\mathrm{Ti}}$ & 0.1 & 0.454 & 0.368 & 0.317 & 0.144 & 0.105 & 0.266 & 0.224 & 0.195 & 0.144 & 0.113 \\
\hline Parameter & 03 & $\mathbf{A}_{\mathrm{t}}$ & $\mathbf{A}_{\mathrm{sv}}$ & $\mathbf{A}_{\mathrm{c}}$ & $f_{\mathrm{c}}$ & $h$ & $f_{\mathrm{c}}$ & $\mathbf{A}_{\mathrm{t}}$ & $h$ & $\mathbf{A}_{\mathrm{sv}}$ & $L$ \\
\hline$S_{\mathrm{Ti}}$ & .0 & 0.652 & 0.21 & 0.168 & 0.108 & 0.067 & 0.336 & 0.289 & 0.154 & 0.135 & 0.113 \\
\hline Parameter & 05 & $\mathbf{A}_{\mathrm{t}}$ & $\mathbf{A}_{\mathrm{sv}}$ & $\mathbf{A}_{\mathrm{c}}$ & $f_{\mathrm{c}}$ & $h$ & $\mathbf{A}_{\mathrm{t}}$ & $\mathbf{A}_{\mathrm{sv}}$ & $\mathbf{A}_{\mathrm{c}}$ & $f_{\mathrm{y}}$ & $h$ \\
\hline \multirow[t]{2}{*}{$S_{\mathrm{Ti}}$} & 0.0 & 0.455 & 0.353 & 0.32 & 0.319 & 0.044 & 0.655 & 0.317 & 0.223 & 0.078 & 0.072 \\
\hline & $\eta_{\text {ave }}$ & \multicolumn{5}{|c|}{$P_{\mathrm{s} 3}($ crack width $=1 \mathrm{~mm})$} & \multicolumn{5}{|c|}{$P_{\mathrm{u}}($ failure $)$} \\
\hline Parameter & 0 & $\mathbf{A}_{\mathrm{c}}$ & $\mathbf{A}_{\mathrm{sv}}$ & $\mathbf{A}_{\mathrm{t}}$ & $f_{\mathrm{y}}$ & $f_{\mathrm{c}}$ & $f_{\mathrm{y}}$ & $\mathbf{A}_{\mathrm{sv}}$ & $\mathbf{A}_{\mathrm{t}}$ & $\mathbf{A}_{\mathrm{c}}$ & $h$ \\
\hline$S_{\mathrm{Ti}}$ & 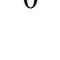 & 0.461 & 0.418 & 0.259 & 0.196 & 0.114 & 0.817 & 0.088 & 0.051 & 0.050 & 0.032 \\
\hline Parameter & 01 & $f_{\mathrm{y}}$ & $\mathbf{A}_{\mathrm{t}}$ & $\mathbf{A}_{\mathrm{c}}$ & $\mathbf{A}_{\mathrm{sv}}$ & $L$ & $f_{\mathrm{y}}$ & $\mathbf{A}_{\mathrm{t}}$ & $\mathbf{A}_{\mathrm{sv}}$ & $\mathbf{A}_{\mathrm{c}}$ & $h$ \\
\hline$S_{\mathrm{Ti}}$ & 0.1 & 0.784 & 0.111 & 0.058 & 0.052 & 0.035 & 0.730 & 0.103 & 0.085 & 0.071 & 0.041 \\
\hline Parameter & 03 & $\mathbf{A}_{\mathrm{t}}$ & $f_{\mathrm{y}}$ & $\mathbf{A}_{\mathrm{c}}$ & $\mathbf{A}_{\mathrm{sv}}$ & $h$ & $\mathbf{A}_{\mathrm{t}}$ & $f_{\mathrm{y}}$ & $\mathbf{A}_{\mathrm{sv}}$ & $\mathbf{A}_{\mathrm{c}}$ & $h$ \\
\hline$S_{\mathrm{Ti}}$ & 0.3 & 0.496 & 0.475 & 0.052 & 0.051 & 0.013 & 0.503 & 0.480 & 0.036 & 0.035 & 0.009 \\
\hline Parameter & 05 & $\mathbf{A}_{\mathrm{t}}$ & $f_{\mathrm{y}}$ & $\mathbf{A}_{\mathrm{sv}}$ & $\mathbf{A}_{\mathrm{c}}$ & $c$ & $\mathbf{A}_{\mathrm{t}}$ & $f_{\mathrm{y}}$ & $\mathbf{A}_{\mathrm{c}}$ & $\mathbf{A}_{\mathrm{sv}}$ & $h$ \\
\hline$S_{\mathrm{Ti}}$ & 0.5 & 0.606 & 0.367 & 0.063 & 0.049 & 0.01 & 0.617 & 0.351 & 0.058 & 0.057 & 0.019 \\
\hline
\end{tabular}

For other values of $i_{\text {corr }}$ and $\eta_{\text {ave }}$ and all considered limit states, the results given in Table A1 (Appendix) indicate that for a small corrosion degree $\left(\eta_{\text {ave }}=0.1\right)$, a variation of $i_{\text {corr }}$ does not significantly affect the order of the more influencing parameters as well as the corresponding $S_{\mathrm{Ti}}$ values; however, for the most pessimistic scenario $\left(i_{\text {corr }}=0.1 \mu \mathrm{A} / \mathrm{cm}^{2}, \eta_{\text {ave }}\right.$ $=0.1), \mathbf{A}_{\mathbf{t}}$ becomes the more critical parameter. It demonstrates that rising corrosion rate could increase the contribution of tension bars at a high corrosion degree, which is consistent with the analysis in Section 5.3.3 that high corrosion degree and rate increase the probability of tension bar breaking.

The $S_{\mathrm{Ti}}$ of $\mathbf{A}_{\mathrm{sv}}, \mathbf{A}_{\mathrm{c}}$, and $\mathbf{A}_{\mathrm{t}}$ are presented in Fig. 17 to further investigate the spatial effects of corrosion non-uniformity. Given the $i_{\text {corr }}$ of $3 \mu \mathrm{A} / \mathrm{cm}^{2}$ and the $\eta_{\text {ave }}$ of 0.5 , the $\mathrm{S}_{\mathrm{Ti}}$ of $\mathbf{A}_{s v}$ and $\mathbf{A}_{c}$ under $P_{\mathrm{s} 1}$ and $P_{\mathrm{s} 2}$ are higher than those of $P_{\mathrm{s} 3}$ and $P_{\mathrm{u}}$, while the $\mathrm{S}_{\mathrm{Ti}}$ of $\mathbf{A}_{t}$ under $P_{\mathrm{s} 1}$ 
is basically lower than $P_{\mathrm{s} 2}, P_{\mathrm{s} 3}$, and $P_{\mathrm{u}}$. Also, being different from Fig. 17a and b, the $\mathrm{S}_{\mathrm{Ti}}$ in Fig. 17c is principally concentrated among $A_{\mathrm{t}, 5}, A_{\mathrm{t}, 6}, A_{\mathrm{t}, 7}$, and $A_{\mathrm{t}, 8}$. Besides, Fig. 17d shows that the $\mathrm{S}_{\mathrm{Ti}}$ of $\mathbf{A}_{t}$ mostly concentrates on $A_{\mathrm{t}, 5}, A_{\mathrm{t}, 6}, A_{\mathrm{t}, 7}$, and $A_{\mathrm{t}, 8} ;$ the $\mathrm{S}_{\mathrm{Ti}}$ of $\mathbf{A}_{t}$ under $P_{\mathrm{s} 1}$ and the $\eta_{\text {ave }}$ of 0.1 is higher than other limit states. Thus, it could be found that the tension bar presents the most significant non-stationary spatial effects with maximum values in the center of the beam span. This is related to a larger presence of open cracks in this central area (Fig. 9) that could accelerate corrosion-induced deterioration. Besides, the sensitivity factors increase with the average corrosion degree.

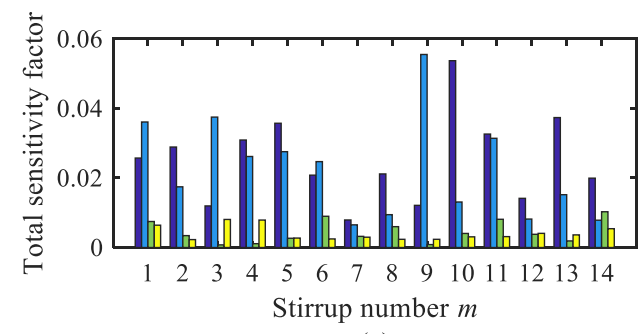

(a)

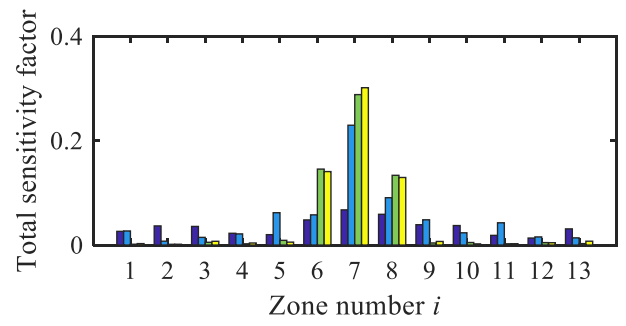

(c)

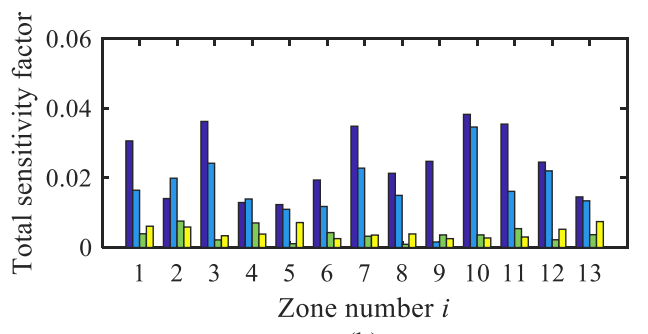

(b)

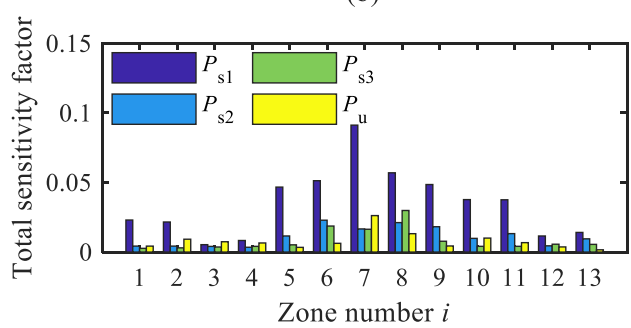

(d)

Fig. 17. Comparisons of $S_{\mathrm{Ti}}$ of $\mathbf{A}_{s v}, \mathbf{A}_{c}$, and $\mathbf{A}_{\mathrm{t}}$ under different scenarios:

(a) $\mathbf{A}_{\mathrm{sv}}, i_{\text {corr }}=3 \mu \mathrm{A} / \mathrm{cm}^{2}, \eta_{\text {ave }}=0.5$; (b) $\mathbf{A}_{\mathrm{c}}, i_{\text {corr }}=3 \mu \mathrm{A} / \mathrm{cm}^{2}, \eta_{\text {ave }}=0.5$;

(c) $\mathbf{A}_{\mathrm{t}}, i_{\text {corr }}=3 \mu \mathrm{A} / \mathrm{cm}^{2}, \eta_{\text {ave }}=0.5$; and (d) $\mathbf{A}_{\mathrm{t}}, i_{\text {corr }}=3 \mu \mathrm{A} / \mathrm{cm}^{2}, \eta_{\text {ave }}=0.1$

Finally, for other values of $i_{\text {corr }}$ and $\eta_{\text {ave }}$ and $P_{\mathrm{u}}$, results in Fig. A1 (Appendix) indicated that a high corrosion current density might induce a failure that happened at critical cross-sections, i.e., close to the mid-span, but a low corrosion current density might cause a failure that occurred at non-critical cross-sections. In other words, a low corrosion current density might induce a higher spatial variation. 


\section{Conclusions}

In this paper, a probabilistic analysis framework for the corroded $\mathrm{RC}$ beams integrating experiments, FEM, and PCE is established to perform performance assessment, failure analysis, and global SA. On this basis, a series of numerical cases are undertaken to present the feasibility of the developed framework, and the following conclusions are drawn:

1) Comparing the FEM simulations with experimental results, it can be concluded that the proposed FEM based modeling strategies are feasible and efficient. In addition, the numerical results indicate that the corrosion degree mainly influences the deflection, load capacity, distributions of concrete crack and reinforcement stress, and failure modes of corroding RC structures, which is consistent with experimental studies. Also, the bond condition may have little effect on the crack pattern and the external load of ULS. However, it may affect the deformation of the RC structure, the mechanical behavior of SLS, the stress distribution of the steel bar, and the failure mode.

2) Based on MCS and the verified FEM model, PCE-based surrogate models for different critical loads in various limit states and scenarios are established. Results demonstrate that the deviation of PCE is relatively small, and the capacity distribution of PCE fits well with MCS. Also, probabilistic failure analysis shows that the concrete crushing dominates the failure mode of the uncorroded $\mathrm{RC}$ beam. For the corroded $\mathrm{RC}$ beam, tension bar breaking becomes the principal failure mode. At low corrosion rates, the probability of stirrup breaking increases with average corrosion degree and vice versa at high corrosion rates.

3) On the other hand, the results of global SA indicate that sensitivity factors of all input variables may vary with average corrosion degree and corrosion current density. Besides, the spatial variability from non-uniform corrosion is reflected in the sensitivity factors of the cross-sectional distribution of the tension bars. Results also show that a high average corrosion degree and corrosion current density increase the probability of failure at the mid-span of the RC beam. For all limit states, the sensitivity factors concentrate on the mid-span of the RC beam and increase with an average corrosion degree. 
In summary, this study provides an efficient and feasible framework for the probabilistic performance and failure analyses of corroded RC structures. Such a framework integrates the merits of the experimental study, FEM simulation, and statistical analysis and could be further used for optimizing life-cycle design and maintenance operations. In the future, more advanced configuration models should be developed to obtain more accurate and detailed results, such as crack width estimation, to update and improve the developed framework.

\section{Acknowledgments}

Funding: The study has been supported by National Key R\&D Program of China (No. 2019YFB1600702), Research Grants Council of the Hong Kong Special Administrative Region, China (No. T22-502/18-R, No. PolyU 15219819, and France/HK Joint Research

Scheme F-PolyU505/18), and National Natural Science Foundation of China (Grant No. 51808476). The third author gratefully acknowledges the financial support from the Regional Council of 'Pays de la Loire' within the framework of the BUENO 2018-2021 research program (Durable Concrete for Offshore Wind Turbines).

\section{References}

[1] D.M. Frangopol, Y. Dong, S. Sabatino, Bridge life-cycle performance and cost: analysis, prediction, optimisation and decision-making, Struct. Infrastruct. Eng. 13 (2017) 1239-1257. doi:10.1080/15732479.2016.1267772.

[2] B. Tu, Y. Dong, Z. Fang, Time-Dependent Reliability and Redundancy of Corroded Prestressed Concrete Bridges at Material, Component, and System Levels, J. Bridg. Eng. 24 (2019). doi:10.1061/(ASCE)BE.1943-5592.0001461.

[3] Z. Wang, W. Jin, Y. Dong, D.M. Frangopol, Hierarchical life-cycle design of reinforced concrete structures incorporating durability, economic efficiency and green objectives, Eng. Struct. 157 (2018) 119-131. doi:10.1016/j.engstruct.2017.11.022.

[4] G. Koch, J. Varney, N. Thopson, O. Moghissi, M. Gould, J. Payer, International Measures of Prevention, Application, and Economics of Corrosion Technologies Study, 2016.

[5] Y. Du, L.A. Clark, A.H.C.C. Chan, Impact of reinforcement corrosion on ductile behavior of reinforced concrete beams, ACI Struct. J. 104 (2007) 285-293. doi:10.14359/18618. 
[6] Z. Ye, W. Zhang, X. Gu, Deterioration of shear behavior of corroded reinforced concrete beams, Eng. Struct. 168 (2018) 708-720.

doi:10.1016/j.engstruct.2018.05.023.

[7] A. Recupero, N. Spinella, F. Tondolo, Failure analysis of corroded RC beams subjected to shear-flexural actions, Eng. Fail. Anal. 93 (2018) 26-37.

doi:10.1016/j.engfailanal.2018.06.025.

[8] A.N. Kallias, M. Imran Rafiq, Finite element investigation of the structural response of corroded RC beams, Eng. Struct. 32 (2010) 2984-2994. doi:10.1016/j.engstruct.2010.05.017.

[9] I. Sæther, S. Sand, FEM simulations of reinforced concrete beams attacked by corrosion, Nord. Concr. Res. 39, 15-32. (2016) 15-32.

[10] E.A.P. Liberati, C.G. Nogueira, E.D. Leonel, A. Chateauneuf, Failure analysis of reinforced concrete structures subjected to chloride penetration and reinforcements corrosion, Elsevier Ltd., 2016. doi:10.1016/B978-0-08-100116-5.00005-3.

[11] H.Y. Guo, Y. Dong, X.L. Gu, Durability assessment of reinforced concrete structures considering global warming: A performance-based engineering and experimental approach, Constr. Build. Mater. 233 (2020) 117251.

doi:10.1016/j.conbuildmat.2019.117251.

[12] X.L. Gu, H.Y. Guo, B. Bin Zhou, W.P. Zhang, C. Jiang, Corrosion non-uniformity of steel bars and reliability of corroded RC beams, Eng. Struct. 167 (2018) 188-202. doi:10.1016/j.engstruct.2018.04.020.

[13] H.Y. Guo, Y. Dong, X.L. Gu, Two-step translation method for time-dependent reliability of structures subject to both continuous deterioration and sudden events, Eng. Struct. 225 (2020) 111291. doi:10.1016/j.engstruct.2020.111291.

[14] V. Sarveswaran, M.B. Roberts, J.A. Ward, Reliability assessment of deteriorating reinforced concrete beams, Proc. Inst. Civ. Eng. Struct. Build. 140 (2000) 239-247. doi:10.1680/stbu.2000.140.3.239.

[15] M.G. Stewart, A. Al-Harthy, Pitting corrosion and structural reliability of corroding RC structures: Experimental data and probabilistic analysis, Reliab. Eng. Syst. Saf. 93 (2008) 373-382. doi:10.1016/j.ress.2006.12.013.

[16] C.Q. Li, R.E. Melchers, Time-dependent risk assessment of structural deterioration caused by reinforcement corrosion, ACI Struct. J. 102 (2005) 754-762. doi:10.14359/14671.

[17] M.G. Stewart, Spatial variability of pitting corrosion and its influence on structural fragility and reliability of RC beams in flexure, Struct. Saf. 26 (2004) 453-470. doi:10.1016/j.strusafe.2004.03.002.

[18] M. Zhang, H. Song, S. Lim, M. Akiyama, D.M. Frangopol, Reliability estimation of corroded RC structures based on spatial variability using experimental evidence, probabilistic analysis and finite element method, Eng. Struct. 192 (2019) 30-52. doi:10.1016/j.engstruct.2019.04.085.

[19] D. V. Val, L. Chernin, Serviceability reliability of reinforced concrete beams with corroded reinforcement, J. Struct. Eng. 135 (2009) 896-905. doi:10.1061/(ASCE)0733-9445(2009)135:8(896). 
[20] E. Bastidas-Arteaga, Reliability of Reinforced Concrete Structures Subjected to Corrosion-Fatigue and Climate Change, Int. J. Concr. Struct. Mater. 12 (2018). doi:10.1186/s40069-018-0235-x.

[21] K. Bergmeister, D. Novak, R. Pukl, V. Červenka, Structural assessment and reliability analysis for existing engineering structures, theoretical background, Struct. Infrastruct. Eng. 5 (2009) 267-275. doi:10.1080/15732470601185612.

[22] M.M. Kioumarsi, M.A.N. Hendriks, M. Geiker, Interference of Localised Corrosion on Adjacent Reinforcement Bars of a Beam in Bending, Concr. Innov. Conf. (2014).

[23] A. Ahmed, Simplified and advanced approaches for the probabilistic analysis of shallow foundations (PhD Thesis), University of Nantes, France, 2012.

[24] P. Ni, Y. Xia, J. Li, H. Hao, Using polynomial chaos expansion for uncertainty and sensitivity analysis of bridge structures, Mech. Syst. Signal Process. 119 (2019) 293311. doi:10.1016/j.ymssp.2018.09.029.

[25] E. Bastidas-Arteaga, C.P. El Soueidy, O. Amiri, P.T. Nguyen, Polynomial chaos expansion for lifetime assessment and sensitivity analysis of reinforced concrete structures subjected to chloride ingress and climate change, Struct. Concr. (2020). doi:10.1002/suco.201900398.

[26] T.N.O. Diana, DIANA User's manual, Manie, J.(Ed.). (2017).

[27] S. Imperatore, A. Leonardi, Z. Rinaldi, Mechanical behaviour of corroded rebars in reinforced concrete elements, Lect. Notes Appl. Comput. Mech. 61 (2012) 207-220. doi:10.1007/978-3-642-24638-8_13.

[28] D.M. Frangopol, K.-Y. Lin, A.C. Estes, Reliability of Reinforced Concrete Girders under Corrosion Attack, J. Struct. Eng. 123 (1997) 286-297. doi:10.1061/(asce)0733-9445(1997)123:3(286).

[29] L. Yu, R. François, V.H. Dang, V. L’Hostis, R. Gagné, Distribution of corrosion and pitting factor of steel in corroded RC beams, Constr. Build. Mater. 95 (2015) 384-392. doi:10.1016/j.conbuildmat.2015.07.119.

[30] W.J. Zhu, R. François, Corrosion of the reinforcement and its influence on the residual structural performance of a 26-year-old corroded RC beam, Constr. Build. Mater. 51 (2014) 461-472. doi:10.1016/j.conbuildmat.2013.11.015.

[31] M.M. Kashani, A.J. Crewe, N.A. Alexander, Use of a 3D optical measurement technique for stochastic corrosion pattern analysis of reinforcing bars subjected to accelerated corrosion, Corros. Sci. 73 (2013) 208-221. doi:10.1016/j.corsci.2013.03.037.

[32] J.A.A. González, C. Andrade, C. Alonso, S. Feliu, J.A.A. González, C. Andrade, C. Alonso, S. Feliu, J. Gonzalez, C. Andrade, C. Alonso, S. Feliu, Comparison of rates of general corrosion and maximum pitting penetration on concrete embedded steel reinforcement, Cem. Concr. Res. 25 (1995) 257-264. doi:10.1016/0008-8846(95)00006-2.

[33] M.S. Darmawan, Pitting corrosion model for reinforced concrete structures in a chloride environment, Mag. Concr. Res. 62 (2010) 91-101. doi:10.1680/macr.2008.62.2.91. 
[34] F. Tang, Z. Lin, G. Chen, W. Yi, Three-dimensional corrosion pit measurement and statistical mechanical degradation analysis of deformed steel bars subjected to accelerated corrosion, Constr. Build. Mater. 70 (2014) 104-117.

doi:10.1016/j.conbuildmat.2014.08.001.

[35] F.J. Vecchio, M.P. Collins, The modified compression-field theory for reinforced concrete elements subjected to shear, ACI J. Proc. 83 (1986) 219-231. doi:10.14359/10416.

[36] M. Tahershamsi, Structural effects of reinforcement corrosion in concrete structures (PhD Thesis), Chalmers University of Technology Gothenburg, Sweden, 2016.

[37] D. Coronelli, K.Z. Hanjari, K. Lundgren, Severely Corroded RC with Cover Cracking, J. Struct. Eng. 139 (2013) 221-232. doi:10.1061/(ASCE)ST.1943-541X.0000633.

[38] D.A. Horidijk, Local approach to fatigue of concrete (PhD Thesis), Delft University of Technology, The Netherlands, 1991.

[39] P.H. Feenstra, Computational aspects of biaxial stress in plain and reinforced concrete (PhD Thesis), Delft University of Technology, The Netherlands, 1993.

[40] N.M.C. fib special activity group, L. Taerwe, S. Matthys, fib Model Code for Concrete Structures 2010, Ernst \& Sohn, Wiley, 2013. doi:10.1002/9783433604090.

[41] F.J. Vecchio, M.P. Collins, Compression response of cracked reinforced concrete, J. Struct. Eng. (United States). 121 (1995) 1153. doi:10.1061/(ASCE)0733-9445(1995)121:7(1153).

[42] L. Berto, P. Simioni, A. Saetta, Numerical modelling of bond behaviour in RC structures affected by reinforcement corrosion, Eng. Struct. 30 (2008) 1375-1385. doi:10.1016/j.engstruct.2007.08.003.

[43] W.P. Zhang, X. Bin Song, X.L. Gu, S. Bin Li, Tensile and fatigue behavior of corroded rebars, Constr. Build. Mater. 34 (2012) 409-417. doi:10.1016/j.conbuildmat.2012.02.071.

[44] C.A. Apostolopoulos, M.P. Papadopoulos, Tensile and low cycle fatigue behavior of corroded reinforcing steel bars S400, Constr. Build. Mater. 21 (2007) 855-864. doi:10.1016/j.conbuildmat.2005.12.012.

[45] W.P. Zhang, H. Chen, X.L. Gu, Tensile behaviour of corroded steel bars under different strain rates, Mag. Concr. Res. 68 (2016) 127-140. doi:10.1680/jmacr.15.00174.

[46] D. V. Val, Deterioration of strength of RC beams due to corrosion and its influence on beam reliability, J. Struct. Eng. 133 (2007) 1297-1306. doi:10.1061/(ASCE)0733-9445(2007)133:9(1297).

[47] Y.H. Zeng, X.L. Gu, W.P. Zhang, Q. Huang, Study on mechanical properties of corroded prestressed tendons, J. Build. Mater. 13 (2010) 169-174.

[48] W.P. Zhang, D.F. Shang, X.L. Gu, Stress-Strain relationship of corroded steel bars, J. Tongji Univ. Sci. 5 (2006) 586 (In Chinese).

[49] T. El Maaddawy, K. Soudki, T. Topper, P.H. Bischoff, Analytical model to predict nonlinear flexural behavior of corroded reinforced concrete beams, ACI Struct. J. 103 (2006) 469-472. 
[50] E. Maaddawy, K. Soudki, T. Topper, Analytical Model to Predict Non-Linear Flexural Behavior of Corroded Analytical Model to Predict Nonlinear Flexural Behavior of, ACI Struct. J. 4 (2005) 550-559.

[51] I. Radović, I.M. Sobol, R.F. Tichy, Quasi-Monte Carlo methods for numerical integration: Comparison of different low discrepancy sequences, Monte Carlo Methods Appl. 2 (1996) 1-14. doi:10.1515/mcma.1996.2.1.1.

[52] R.G. Ghanem, P.D. Spanos, Stochastic finite elements: a spectral approach, Courier Corporation, 2003.

[53] B. Sudret, Global sensitivity analysis using polynomial chaos expansions, Reliab. Eng. Syst. Saf. 93 (2008) 964-979. doi:10.1016/j.ress.2007.04.002.

[54] S. Marelli, B. Sudret, UQLab user manual - Polynomial Chaos Expansions, Rep. UQLab-V0.9-104, Chair Risk, Saf. Uncertain. Quantif. ETH Zurich,. (2015) 1-52.

[55] S. Kucherenko, D. Albrecht, A. Saltelli, Exploring multi-dimensional spaces: A comparison of Latin hypercube and quasi Monte Carlo sampling techniques, ArXiv Prepr. ArXiv1505.02350. 165 (2015) 222-238. doi:10.1016/j.ress.2017.04.003.

[56] A. Saltelli, T. Homma, Importance measures in global sensitivity analysis of model output, Reliab. Eng. Sys. Saf. 52 (1996) 1-17.

[57] R. Lu, Y. Luo, J.P. Conte, Reliability evaluation of reinforced concrete beams, Struct. Saf. 14 (1994) 277-298. doi:10.1016/0167-4730(94)90016-7.

[58] F. Duprat, Reliability of RC beams under chloride-ingress, Constr. Build. Mater. 21 (2007) 1605-1616. doi:10.1016/j.conbuildmat.2006.08.002.

[59] E. Bastidas-Arteaga, F. Schoefs, M.G. Stewart, X. Wang, Influence of global warming on durability of corroding RC structures: A probabilistic approach, Eng. Struct. 51 (2013) 259-266. doi:10.1016/j.engstruct.2013.01.006.

[60] M.S. Darmawan, M.G. Stewart, Spatial time-dependent reliability analysis of corroding pretensioned prestressed concrete bridge girders, Struct. Saf. 29 (2007) 1631. doi:10.1016/j.strusafe.2005.11.002.

[61] B. Šavija, M. Luković, J. Pacheco, E. Schlangen, Cracking of the concrete cover due to reinforcement corrosion: A two-dimensional lattice model study, Constr. Build. Mater. 44 (2013) 626-638. doi:10.1016/j.conbuildmat.2013.03.063.

[62] DS/EN 1992-1-1, Eurocode 2 : Design of concrete structures - Part 1-1: General rules and rules for buildings, (1992).

[63] M.G. Stewart, X. Wang, M.N. Nguyen, Climate change impact and risks of concrete infrastructure deterioration, Eng. Struct. 33 (2011) 1326-1337. doi:10.1016/j.engstruct.2011.01.010.

[64] L. Breiman, W. Meisel, E. Purcell, Variable kernel estimates of multivariate densities, Technometrics. 19 (1977) 135-144. doi:10.1080/00401706.1977.10489521. 


\section{Appendix: Supplementary results for the sensitivity analysis}

In order to consider the effects of $i_{\text {corr }}$ and $\eta_{\text {ave }}$ on the SA analysis, four scenarios are selected: (a) $i_{\text {corr }}=0.1 \mu \mathrm{A} / \mathrm{cm}^{2}, \eta_{\text {ave }}=0.1$, (b) $i_{\text {corr }}=0.1 \mu \mathrm{A} / \mathrm{cm}^{2}, \eta_{\text {ave }}=0.5$, (c) $i_{\text {corr }}=3 \mu \mathrm{A} / \mathrm{cm}^{2}, \eta_{\text {ave }}=$ 0.1 , and (d) $i_{\text {corr }}=3 \mu \mathrm{A} / \mathrm{cm}^{2}, \eta_{\text {ave }}=0.5$. The SA analysis results are listed in Table A1. Comparing scenarios (a) with (c), when $\eta_{\mathrm{ave}}=0.1, \mathbf{A}_{\mathrm{t}}$ and $\mathbf{A}_{\mathrm{c}}$ are the most influencing factors for $P_{\mathrm{s} 1} ; f_{\mathrm{c}}$ and $L$ are the most significant factors for $P_{\mathrm{s} 2}$; and for $P_{\mathrm{s} 3}$ and $P_{\mathrm{u}}$, the sensitivities of $f_{\mathrm{y}}$ and $\mathbf{A}_{\mathrm{t}}$ become the greatest. It can be noticed in Table A1a and $\mathrm{c}$ that the rank of input variables remains unchanged, and the corresponding values do not change much, indicating that the corrosion rate does not influence much the $S_{\mathrm{Ti}}$ of input variables at the low corrosion degree. Thus, the contribution of the cross-sectional distribution of steel bars is not only affected by corrosion current density, corrosion degree but also limit states. High corrosion current density and corrosion degree can increase the $S_{\text {Ti }}$ of the cross-sectional distribution of steel bars. However, for scenarios (b) and (d), the $S_{\mathrm{Ti}}$ of input variables are quite different. In scenario (b), the $S_{\mathrm{Ti}}$ of $\mathbf{A}_{\mathrm{sv}}$ is the top one for $P_{\mathrm{s} 1}$ and $P_{\mathrm{s} 2}$; the $S_{\mathrm{Ti}}$ of $\mathbf{A}_{\mathrm{t}}$ and $f_{\mathrm{c}}$ are the largest for $P_{\mathrm{s} 3}$ and $P_{\mathrm{u}}$, respectively. Meanwhile, in scenario (d), the $S_{\mathrm{Ti}}$ of $\mathbf{A}_{\mathrm{t}}$ is much higher than other input variables for all critical loads.

Concerning the influences of $i_{\text {corr }}$ and $\eta_{\text {ave }}$ on the spatial effect of cross-sectional areas, Fig. A1 shows the sensitivity factors of $\mathbf{A}_{\mathrm{t}}$ for $P_{\mathrm{u}}$ under the $i_{\text {corr }}$ of 0.1 and $3 \mu \mathrm{A} / \mathrm{cm}^{2}$. Most sensitivity factors concentrate among $A_{\mathrm{t}, 6}, A_{\mathrm{t}, 7}$, and $A_{\mathrm{t}, 8}$, like Fig. 17c. As indicated in Fig. A1a, when the $\eta_{\text {ave }}$ is below 0.5 , the sensitivity factor of $A_{\mathrm{t}, 7}$ is the largest, followed by $A_{\mathrm{t}, 6}$ and $A_{\mathrm{t}, 8}$, but the sensitivity factor of $A_{\mathrm{t}, 8}$ becomes the largest when the $\eta_{\text {ave }}$ reaches 0.5 . In Fig. A1b, the sensitivity factor of $A_{\mathrm{t}, 8}$ is always the largest. Besides, when the $\eta_{\text {ave }}$ reaches 0.5 , comparing Fig. A1a with $\mathrm{b}$, although the sensitivity factors of $A_{\mathrm{t}, 6}, A_{\mathrm{t}, 7}$ and $A_{\mathrm{t}, 8}$ are lower, the sensitivity factors within all $A_{\mathrm{t}, \mathrm{i}}$ distributed more uniformly in Fig. A1a. 
Table A1 Comparisons of $S_{\mathrm{Ti}}$ among different corrosion scenarios

\begin{tabular}{|c|c|c|c|c|c|c|c|c|c|c|c|}
\hline \multirow{3}{*}{$\begin{array}{c}\text { Scenario } \\
\text { Parameter } \\
S_{\mathrm{Ti}}\end{array}$} & \multirow{3}{*}{$\begin{array}{c}\text { Limit state } \\
P_{\mathrm{s} 1}\end{array}$} & \multicolumn{5}{|c|}{ (a) $i_{\text {corr }}=0.1 \mu \mathrm{A} / \mathrm{cm}^{2}, \eta_{\text {ave }}=0.1$} & \multicolumn{5}{|c|}{ (b) $i_{\text {corr }}=0.1 \mu \mathrm{A} / \mathrm{cm}^{2}, \eta_{\mathrm{ave}}=0.5$} \\
\hline & & $\mathbf{A}_{\mathbf{t}}$ & $\mathbf{A}_{\mathrm{c}}$ & $f_{c}$ & $\mathbf{A}_{\text {sv }}$ & $E_{s}$ & $\mathbf{A}_{\mathbf{s v}}$ & $\mathbf{A}_{\mathbf{t}}$ & $f_{c}$ & $\mathbf{A}_{\mathrm{c}}$ & $f_{\mathrm{y}}$ \\
\hline & & 0.313 & 0.299 & 0.280 & 0.275 & 0.087 & 0.368 & 0.328 & 0.307 & 0.273 & 0.085 \\
\hline Parameter & \multirow{2}{*}{$P_{\mathrm{s} 2}$} & $f_{c}$ & $L$ & $h$ & $\mathbf{A}_{\mathbf{t}}$ & $E_{s}$ & $\mathbf{A}_{\text {sv }}$ & $\mathbf{A}_{\mathrm{c}}$ & $\mathbf{A}_{\mathbf{t}}$ & $c$ & $f_{\mathrm{y}}$ \\
\hline$S_{\mathrm{Ti}}$ & & 0.270 & 0.220 & 0.189 & 0.140 & 0.117 & 0.509 & 0.417 & 0.408 & 0.139 & 0.092 \\
\hline Parameter & \multirow{2}{*}{$P_{\mathrm{s} 3}$} & $f_{\mathrm{y}}$ & $\mathbf{A}_{\mathrm{t}}$ & $\mathbf{A}_{\mathrm{c}}$ & $\mathbf{A}_{\text {sv }}$ & $L$ & $\mathbf{A}_{\mathbf{t}}$ & $f_{\mathrm{y}}$ & $\mathbf{A}_{\mathbf{s v}}$ & $\mathbf{A}_{\mathrm{c}}$ & $L$ \\
\hline$S_{\mathrm{Ti}}$ & & 0.766 & 0.110 & 0.070 & 0.062 & 0.036 & 0.541 & 0.335 & 0.210 & 0.193 & 0.024 \\
\hline Parameter & \multirow{2}{*}{$P_{\mathrm{u}}$} & $f_{\mathrm{y}}$ & $\mathbf{A}_{\mathrm{t}}$ & $\mathbf{A}_{\text {sv }}$ & $\mathbf{A}_{\mathrm{c}}$ & $h$ & $f_{c}$ & $f_{\mathrm{y}}$ & $\mathbf{A}_{\mathbf{t}}$ & $\mathbf{A}_{\mathrm{c}}$ & $\mathbf{A}_{\mathbf{s v}}$ \\
\hline$S_{\mathrm{Ti}}$ & & 0.781 & 0.108 & 0.049 & 0.046 & 0.035 & 0.306 & 0.301 & 0.299 & 0.122 & 0.119 \\
\hline Scenario & Limit state & \multicolumn{5}{|c|}{ (c) $i_{\text {corr }}=3 \mu \mathrm{A} / \mathrm{cm}^{2}, \eta_{\text {ave }}=0.1$} & \multicolumn{5}{|c|}{ (d) $i_{\text {corr }}=3 \mu \mathrm{A} / \mathrm{cm}^{2}, \eta_{\text {ave }}=0.5$} \\
\hline Parameter & \multirow{2}{*}{$P_{\mathrm{s} 1}$} & $\mathbf{A}_{\mathrm{t}}$ & $\mathbf{A}_{\mathrm{sv}}$ & $\mathbf{A}_{\mathrm{c}}$ & $f_{c}$ & $E_{s}$ & $\mathbf{A}_{\mathrm{t}}$ & $\mathbf{A}_{\text {sv }}$ & $\mathbf{A}_{\mathrm{c}}$ & $f_{c}$ & $h$ \\
\hline$S_{\mathrm{Ti}}$ & & 0.454 & 0.368 & 0.317 & 0.144 & 0.105 & 0.455 & 0.353 & 0.320 & 0.319 & 0.044 \\
\hline Parameter & \multirow{2}{*}{$P_{\mathrm{s} 2}$} & $f_{c}$ & $L$ & $h$ & $\mathbf{A}_{\mathrm{t}}$ & $E_{s}$ & $\mathbf{A}_{\mathrm{t}}$ & $\mathbf{A}_{\text {sv }}$ & $\mathbf{A}_{\mathrm{c}}$ & $f_{\mathrm{y}}$ & $h$ \\
\hline$S_{\mathrm{Ti}}$ & & 0.266 & 0.224 & 0.195 & 0.144 & 0.113 & 0.655 & 0.317 & 0.223 & 0.078 & 0.072 \\
\hline Parameter & \multirow{2}{*}{$P_{\mathrm{s} 3}$} & $f_{\mathrm{y}}$ & $\mathbf{A}_{\mathrm{t}}$ & $\mathbf{A}_{\mathrm{c}}$ & $\mathbf{A}_{\text {sv }}$ & $L$ & $\mathbf{A}_{\mathrm{t}}$ & $f_{\mathrm{y}}$ & $\mathbf{A}_{\text {sv }}$ & $\mathbf{A}_{\mathrm{c}}$ & $c$ \\
\hline$S_{\mathrm{Ti}}$ & & 0.784 & 0.111 & 0.058 & 0.052 & 0.035 & 0.606 & 0.367 & 0.063 & 0.049 & 0.010 \\
\hline Parameter & \multirow{2}{*}{$P_{\mathrm{u}}$} & $f_{\mathrm{y}}$ & $\mathbf{A}_{\mathrm{t}}$ & $\mathbf{A}_{\text {sv }}$ & $\mathbf{A}_{\mathrm{c}}$ & $h$ & $\mathbf{A}_{\mathrm{t}}$ & $f_{\mathrm{y}}$ & $\mathbf{A}_{\mathrm{c}}$ & $\mathbf{A}_{\text {sv }}$ & $h$ \\
\hline$S_{\mathrm{Ti}}$ & & 0.730 & 0.103 & 0.085 & 0.071 & 0.041 & 0.617 & 0.351 & 0.058 & 0.057 & 0.019 \\
\hline
\end{tabular}

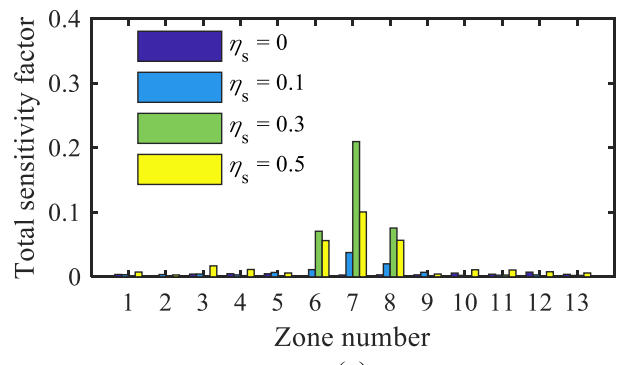

(a)

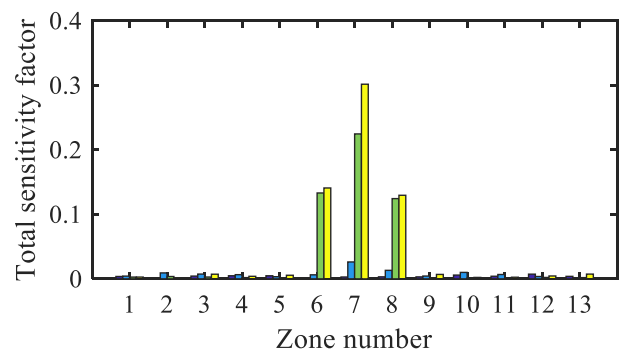

(b)

Fig. A1. Comparisons of $S_{\mathrm{Ti}}$ of $\mathbf{A}_{t}$ for $P_{\mathrm{u}}$ : (a) $i_{\text {corr }}=0.1 \mu \mathrm{A} / \mathrm{cm}^{2}$ and (b) $i_{\text {corr }}=3 \mu \mathrm{A} / \mathrm{cm}^{2}$ 